(C) 2021, The Authors. Published by Elsevier Inc. and Fass Inc. on behalf of the American Dairy Science Association ${ }^{\circledR}$. This is an open access article under the CC BY-NC-ND license (http://creativecommons.org/licenses/by-nc-nd/4.0/).

\title{
Modulation of colostrum composition and fatty acid status in neonatal calves by maternal supplementation with essential fatty acids and conjugated linoleic acid starting in late lactation
}

\author{
K. L. Uken, ${ }^{1} \oplus$ C. T. Schäff, ${ }^{1}$ L. Vogel, 1 M. Gnott, ${ }^{1}$ D. Dannenberger, ${ }^{2} \odot$ S. Görs, ${ }^{1}$ A. Tuchscherer, ${ }^{3}$ \\ A. Tröscher, ${ }^{4}$ (D) W. Liermann, ${ }^{1}$ and H. M. Hammon ${ }^{1 *}$ (D) \\ ${ }^{1}$ Institute of Nutritional Physiology "Oskar Kellner," Leibniz Institute for Farm Animal Biology (FBN), 18196 Dummerstorf, Germany \\ ${ }^{2}$ Institute of Muscle Biology and Growth, Leibniz Institute for Farm Animal Biology (FBN), 18196 Dummerstorf, Germany \\ ${ }^{3}$ Institute of Genetics and Biometry, Leibniz Institute for Farm Animal Biology (FBN), 18196 Dummerstorf, Germany \\ ${ }^{4}$ BASF SE, 68623 Lampertheim, Germany
}

\section{ABSTRACT}

Sufficient maternal supply of essential fatty acids (EFA) to neonatal calves is critical for calf development. In the modern dairy cow, EFA supply has shifted from $\alpha$-linolenic acid (ALA) to linoleic acid (LA) due to the replacement of pasture feeding by corn silagebased diets. As a consequence of reduced pasture feeding, conjugated linoleic acid (CLA) provision by rumen biohydrogenation was also reduced. The present study investigated the fatty acid (FA) status and performance of neonatal calves descended from dams receiving corn silage-based diets and random supplementation of either $76 \mathrm{~g} / \mathrm{d}$ coconut oil (CTRL; $\mathrm{n}=9$ ), $78 \mathrm{~g} / \mathrm{d}$ linseed oil and $4 \mathrm{~g} / \mathrm{d}$ safflower oil (EFA; n-6/n-3 $\mathrm{FA}$ ratio $=1: 3 ; \mathrm{n}=9), 38 \mathrm{~g} / \mathrm{d}$ Lutalin $(\mathrm{BASF} \mathrm{SE}$, Ludwigshafen, Germany) providing $27 \%$ cis-9,trans- 11 and trans-10,cis-12 CLA, respectively (CLA; $\mathrm{n}=9$ ), or a combination of EFA and CLA (EFA+CLA; $\mathrm{n}=$ 11 ) in the last 9 wk before parturition and following lactation. The experimental period comprised the first $5 \mathrm{~d}$ of life, during which calves received colostrum and transition milk from their own dam. The nutrient compositions of colostrum and transition milk were analyzed. Plasma samples were taken after birth and before first colostrum intake and on d 5 of life for FA analyses of the total plasma fat and lipid fractions. Maternal EFA and CLA supplementation partly affected colostrum and transition milk composition but did not change the body weights of calves. Most EFA in calves were found in the phospholipid (PL) and cholesterol ester (CE) fractions of the plasma fat. Maternal EFA supplementation increased the percentage of ALA in all lipid fractions of EFA and EFA+CLA compared with CTRL and CLA calves on d 1 and 5, and the

Received September 11, 2020.

Accepted November 11, 2020.

*Corresponding author: hammon@fbn-dummerstorf.de increase was much greater on $\mathrm{d} 5$ than on $\mathrm{d} 1$. The LA concentration increased from d 1 to 5 in the plasma fat and lipid fractions of all groups. The concentrations of docosapentaenoic acid, docosahexaenoic acid, and arachidonic acid in plasma fat were higher on $\mathrm{d} 1$ than on d 5, and the percentage of n-3 metabolites was mainly increased in PL if dams received EFA. The percentage of cis-9,trans-11 CLA was higher in the plasma fat of EFA+CLA than CTRL calves after birth. By d 5, the percentages of both CLA isomers increased, leading to higher proportions in plasma fat of CLA and EFA+CLA than in CTRL and EFA calves. Elevated cis-9,trans-11 CLA enrichment was observed on d 5 in PL, CE, and triglycerides of CLA-treated calves, whereas trans-10,cis-12 CLA could not be detected in individual plasma fractions. These results suggest that an altered maternal EFA and CLA supply can reach the calf via the placenta and particularly via the intake of colostrum and transition milk, whereas the n-3 and n-6 FA metabolites partly indicated a greater transfer via the placenta. Furthermore, the nutrient supply via colostrum and transition milk might be partly modulated by an altered maternal EFA and CLA supply but without consequences on calf performance during the first $5 \mathrm{~d}$ of life.

Key words: essential fatty acids, conjugated linoleic acid, maternal fatty acid status, neonate

\section{INTRODUCTION}

Essential fatty acids (EFA) include the 2 fatty acids (FA) linoleic acid (LA; 18:2 cis-9, cis-12), an n-6 FA, and $\alpha$-linolenic acid (ALA; 18:3 cis-9,cis-12,cis-15), which is classified as an n-3 FA (Burr and Burr, 1930; Neuringer et al., 1986). Both LA and ALA serve as precursors for PUFA of the n-3 and n- 6 FA series, respectively, that are responsible for many essential functions, such as membrane fluidity, prostaglandin synthesis, and regulation of gene expression (Innis, 
2005; Jump, 2008). Due to their critical role in cognitive development, the long-chain FA derived from LA and ALA are particularly important for the developing fetus (Koletzko et al., 2008). To obtain n-3 and n-6 $\mathrm{FA}$, the fetus depends on the placental transfer of FA via maternal circulation (Innis, 2005). It was stated in previous studies that the transfer of EFA seems to be limited in the epitheliochorial placenta of ruminants, resulting in poor EFA status of neonates (Noble et al., 1978a, 1982). Nevertheless, feeding LA to pregnant dams increased the proportion of this FA in the plasma of neonatal lambs (Noble et al., 1978b). However, EFA transfer by colostrum or milk seems to be of greater importance than placental transfer for neonatal EFA supply in calves (Garcia et al., 2014a, 2016). A significant increase in EFA in milk fat of the colostrum when cows are supplemented with EFA during late gestation was previously shown (Santschi et al., 2009; Garcia et al., 2014a). In addition, a recently published study indicated beneficial effects of n-3 FA supplementation with colostrum on the neonatal inflammatory response in calves (Opgenorth et al., 2020).

Furthermore, EFA can serve as a precursor for CLA, which is synthesized in the rumen (Bauman et al., 2000; Shingfield et al., 2010). Some CLA isomers have healthpromoting effects in mammals (Nagao and Yanagita, 2005; Shokryazdan et al., 2017) but also reveal metabolic effects in dairy cows (Bauman et al., 2000; Hötger et al., 2013; Vogel et al., 2021). Studies in rats and pigs indicate placental and mammary transfers of CLA and that maternal CLA supply influences FA status, fetal development, and metabolism of the offspring (Park et al., 2005; Segovia et al., 2015). However, studies in cattle investigating the effect of maternal CLA supply on fetal and neonatal FA status and development are scarce. The maternal EFA and CLA status in modern dairy herds has changed due to the progressive replacement of pasture by corn silage-based diets (Barkema et al., 2015), which includes a shift from ALA to LA in the dairy ration, decrease of ALA in milk fat by about $300 \%$, and reduced ruminant CLA biosynthesis and CLA in milk fat (about $250-300 \%$ less CLA in milk fat) because of the low EFA intake (Kelly et al., 1998; Kay et al., 2005; Couvreur et al., 2006; Lahlou et al., 2014). As the 2 EFA compete with each other for enzymes involved in the synthesis of their metabolites, changing the ratio of LA to ALA can affect the availability of their metabolites (Geiger et al., 1993; Calder, 2012).

Beyond the FA patterns, maternal supplementation with EFA may affect the nutrient composition of colostrum and milk (Moallem, 2018; Haubold et al., 2020) and the performance of the offspring (Innis, 2005). Previous studies have shown that dietary supplementation of ALA alone or in combination with LA either to preg- nant cows or directly to calves can improve the ADG and feed efficiency of calves (Hill et al., 2009; Garcia et al., 2014b). However, the effect of feeding colostrum and transition milk from dams with an elevated EFA and CLA supply on the development of neonatal calves remains unclear. In a recent study, we showed elevated concentrations of EFA, especially ALA and CLA, in the fat of colostrum and milk when cows were infused with linseed and safflower oil combined with or without CLA infusion during late gestation (Vogel et al., 2020). We hypothesized that changes in maternal EFA and CLA provision during late gestation and early lactation modify the FA status of calves, accordingly. In addition, maternal EFA and CLA supplementation may affect the performance of calves by influencing fetal FA supply and by changing the chemical composition and FA pattern in colostrum and transition milk. To address the FA status of the neonatal calves, FA patterns in calves were measured in several lipid fractions of the blood plasma before first colostrum feeding and on d 5 of life after colostrum and transition milk intake from their respective dam.

\section{MATERIALS AND METHODS}

The experimental procedures were conducted in strict accordance with the German Animal Welfare Act and were approved by the relevant Department for Animal Welfare Affairs of the state of Mecklenburg-West Pomerania, Germany (Landesamt für Landwirtschaft, Lebensmittelsicherheit und Fischerei; LALLF M-V/ TSD/7221.3-1-052/15).

\section{Animals, Experimental Design, and Husbandry}

In the present study, the progeny from 37 German Holstein cows, which were part of an experiment addressing the effect of EFA and CLA during the transition phase, were investigated from December 2015 to September 2017. A detailed description of this experiment was previously published by Vogel et al. (2020). Briefly, dams were fed corn silage-based diets providing a low content of EFA with especially low amounts of $\mathrm{n}-3 \mathrm{FA}(1.4 \mathrm{~g}$ and $9.5 \mathrm{~g}$ of $\mathrm{n}-3$ and $\mathrm{n}-6 \mathrm{FA}$ per $\mathrm{kg}$ of $\mathrm{DM}$, respectively) from the middle of second lactation (wk 22 antepartum) to third lactation. The treatments focused on the supply of FA that provide EFA (mainly ALA), CLA, or the combination of both. Such a treatment model refers to the supply of EFA and related rumen and tissue CLA production in dairy cows receiving fresh grass or on pasture (Kelly et al., 1998; Ferlay et al., 2006; Lahlou et al., 2014) and was described in detail by Vogel et al. (2020). Dams were randomly assigned according to milk yield and BW to 1 of 4 treatments: 
control group (CTRL) receiving $76 \mathrm{~g} / \mathrm{d}$ coconut oil (Bio-Kokosöl \#665, Kräuterhaus Sanct Bernhard KG, Bad Ditzenbach, Germany); EFA in the form of $78 \mathrm{~g} / \mathrm{d}$ linseed oil (DERBY Leinöl \#4026921003087, DERBY Spezialfutter GmbH, Münster, Germany) and $4 \mathrm{~g} / \mathrm{d}$ safflower oil (GEFRO Distelöl, GEFRO Reformversand Frommlet KG, Memmingen, Germany; 38 g/d Lutalin (CLA; cis-9,trans-11, trans-10,cis-12 CLA, $10 \mathrm{~g} / \mathrm{d}$ each; BASF SE, Ludwigshafen, Germany); and a combination of EFA and CLA supplementation (EFA+CLA; $78 \mathrm{~g} / \mathrm{d}$ linseed oil $+4 \mathrm{~g} / \mathrm{d}$ safflower oil $+38 \mathrm{~g} / \mathrm{d}$ Lutalin). As previously reported by Vogel et al. (2020), the CTRL supplement provided less than $1.4 \mathrm{~g} / \mathrm{d}$ EFA. The EFA supplement provided $39.9 \mathrm{~g} / \mathrm{d}$ ALA and $14.9 \mathrm{~g} / \mathrm{d}$ LA. Treatments for CTRL and EFA were iso-energetic. Doses for the supplied EFA (linseed and safflower oil in a ratio of 19.5:1; providing an $n-6 / n-3$ FA ratio of 1:3 in the supplement mixture) and CLA were recently evaluated in a companion dose-response study in midlactating dairy cows (Haubold et al., 2020). Vitamin $\mathrm{E}$ was added to the CTRL and CLA supplements to compensate for naturally occurring vitamin $\mathrm{E}$ in linseed oil, which was applied in the EFA and EFA+CLA groups. The FA were supplemented to the cows from $\mathrm{d}$ 63 before calving until early lactation and were infused directly into the abomasum to avoid ruminal biohydrogenation (Vogel et al., 2020). The amount of supplements were halved during the dry period starting at 6 wk antepartum. For technical reasons, the study was subdivided into 5 consecutive blocks with 7 to 8 calves born per block. In total, 38 calves of the CTRL ( 5 male, 4 female), EFA (4 male, 5 female), CLA (1 male, 8 female), and EFA+CLA (4 male, 7 female; 9 single and one pair of twins: one male, one female) groups were investigated from birth until d 5 of life. Originally 40 cows were fitted with rumen fistula and tube connection to the abomasum in the study (Vogel et al., 2020). Two cows calved prematurely and one calf died during the birth process. Therefore, the calves of 37 cows were included in this study.

Calves were separated from their dam directly after birth and were housed in a climate-controlled room at $19^{\circ} \mathrm{C}$ in single boxes with straw bedding and free access to water. Body weights were recorded before the first feeding after birth and at the end of the experiment on $\mathrm{d} 5$ at $2 \mathrm{~h}$ after feeding. During the experiment, calves were fed colostrum (defined as milk of first $24 \mathrm{~h}$ after calving) and transition milk (defined as milk from d 2 to 5 after calving) from their own dam. If the colostrum quantity of a dam was insufficient, the required amount was achieved by combination with the colostrum from another cow of the same treatment group to ensure that the FA supply was consistent within the treatment group. This happened 4 times (in CTRL and EFA groups). The first meal was fed on average $2.5 \pm 1.7$ $\mathrm{h}$ after birth. Calves were fed colostrum from the first milking in amounts of $10 \%$ of BW during the first 24 $\mathrm{h}$ after birth divided into 2 meals. Colostrum from the second milking after calving was only fed if the amount of first colostrum was not sufficient for the second meal. On d 2 (after $24 \mathrm{~h}$ of birth and before beginning of $\mathrm{d} 3$ of life), calves were fed transition milk from the third milking after calving; feed allowance was $6 \%$ of $\mathrm{BW}$ on d 2 to ensure that all calves received the same amount of transition milk before d 3 of life, irrespective of whether calves were born in the morning or afternoon the day before. From d 3 onward, calves were fed twice daily transition milk of the fifth, seventh, and ninth milkings after calving at $12 \%$ of $\mathrm{BW} / \mathrm{d}$ divided into 2 meals in the morning and evening. The exact nutrient intakes of calves are presented in Table 1. Calves were fed by nipple bottle, and those refusing to drink were tube fed to ensure similar milk intake between individuals. Individual colostrum and milk samples from daily morning and afternoon milkings were taken and stored at $-20^{\circ} \mathrm{C}$ until chemical composition analysis.

\section{Milk Analyses}

Chemical composition analyses were performed for colostrum and transition milk of all milkings (milkings 1-9 from d 1 to 5 after calving) of the study. Thawed samples were homogenized by warming $\left(41^{\circ} \mathrm{C}\right)$ and pivoting before further analyses. Determinations of DM, protein, lactose, and fat were conducted according to the protocol of Görs et al. (2009). For determination of DM, triplicates of $8 \mu \mathrm{L}$ of milk were dried in tin capsules $\left(5 \mathrm{~h}, 55^{\circ} \mathrm{C}\right)$. The mean coefficient of variation for DM in triplicate was $0.6 \%$. Dried samples were subsequently used for nitrogen determination with a mean coefficient of variation of $2.0 \%$ for triplicate nitrogen measurements by an elemental analyzer (EA 1108, Fisons Instr., Rodano Milan, Italy) coupled with a mass spectrometer (delta S interfaced to ConFlo II:Finnigan MAT, Bremen, Germany). Nitrogen was converted into CP by factor 6.38. Fat content was measured according to the Röse-Gottlieb procedure, which was modified by Görs et al. (2009). A volume of $500 \mu \mathrm{L}$ of milk diluted in $500 \mu \mathrm{L}$ of ultra-pure water was used for analyses; the mixture was subjected to shaking for $60 \mathrm{~s}$ for separation of the ether soluble components in each extraction step. To verify the accuracy of single measurements, the same sample was measured 12 times in each block. The mean coefficient of variation of these repeated measurements was $2.7 \%$.

For determination of lactose, $250 \mu \mathrm{L}$ of milk was diluted with $1 \mathrm{~mL}$ of ultra-pure water. Diluted milk was centrifuged $\left(50,000 \times g\right.$ for $20 \mathrm{~min}$ at $\left.4^{\circ} \mathrm{C}\right)$, and 
Uken et al.: MATERNAL FATTY ACID SUPPLY IN CALVES

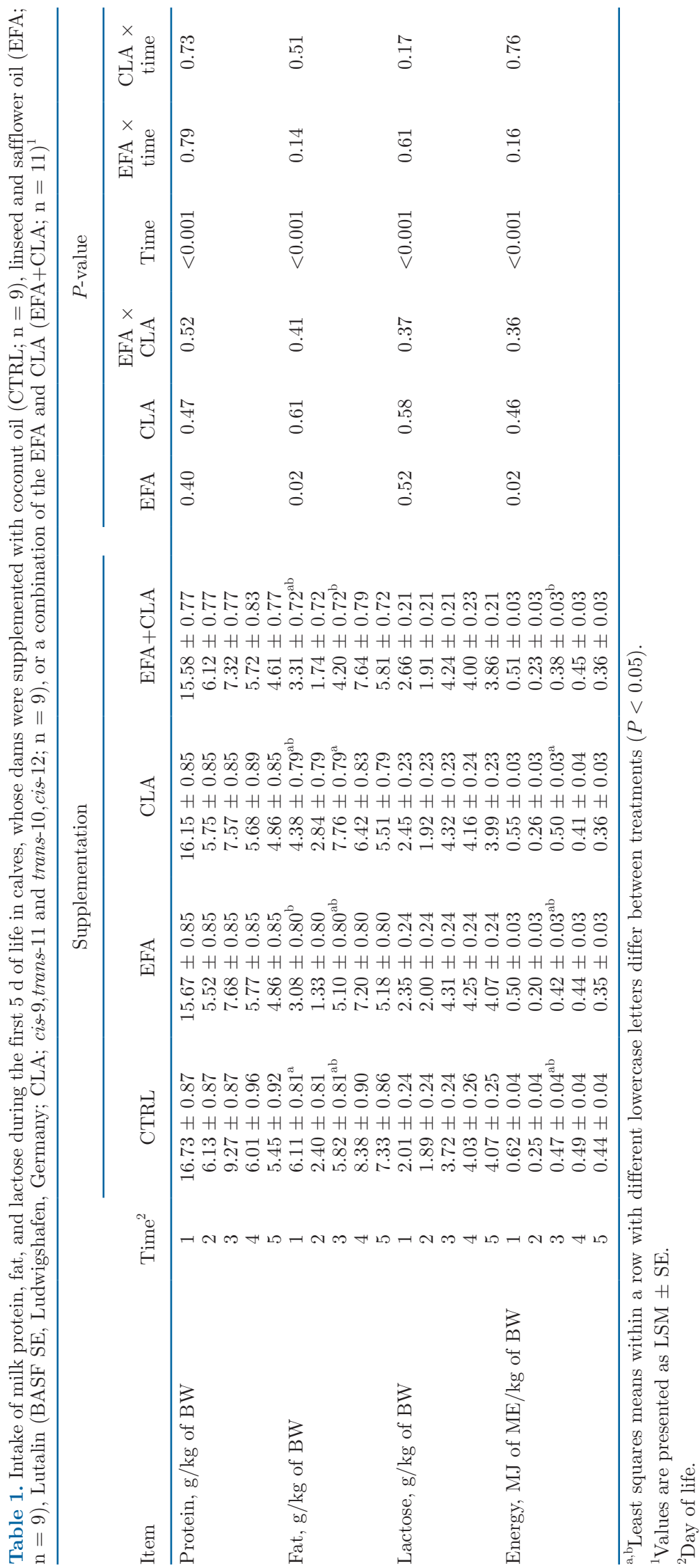


the obtained clear solution was pipetted into a new tube, centrifuged again under the same conditions, and stored at $-20^{\circ} \mathrm{C}$ until further analyses. The subsequent analysis of the lactose concentration in the clear solution was conducted as published by Görs et al. (2009) but with an increased sonication time of $5 \mathrm{~min}$ and a sample volume of $10 \mu \mathrm{L}$ of 50 -fold diluted solution measured by HPLC. The mean coefficient of variation for lactose measurements was $2.4 \%$. The concentrations of the lactose and fat in milk on a $\mathrm{g} / \mathrm{kg}$ basis were computed from concentrations on a $\mathrm{g} / \mathrm{L}$ basis by correcting for the density of milk from the respective milking according to data from Madsen et al. (2004). The energy content in milk was estimated as follows: 17.0, 24.2, and 36.6 MJ of gross energy per $\mathrm{kg}$ of lactose, protein, and fat, respectively; $\mathrm{ME}=0.97 \times 0.96 \times$ gross energy (Kühne et al., 2000; NRC, 2001).

\section{Analyses of Plasma Fatty Acids}

Blood samples were taken directly after birth and before first colostrum intake by venipuncture from the jugular vein using evacuated tubes $(1.2-2 \mathrm{mg}$ of $\mathrm{K}_{3} \mathrm{EDTA} / \mathrm{mL}$, Vacuette, Greiner Bio-One International GmbH, Kremsmünster, Austria). On d 5 of life, blood was sampled in S-Monovette tubes (1.6 mg of $\mathrm{K}_{3}$ EDTA/ mL, Sarstedt AG \& Co., Nümbrecht, Germany) using a catheter (Cavafix Certo with Splittocan, B. Braun Melsungen AG, Melsungen, Germany) inserted into the jugular vein the day before. Blood samples were placed on ice before centrifugation at $2,700 \times g$ and $4^{\circ} \mathrm{C}$ for $20 \mathrm{~min}$. The obtained plasma samples were stored at $-20^{\circ} \mathrm{C}$ until $\mathrm{FA}$ analyses.

Extraction of plasma lipids was conducted as described by Dannenberger et al. (2017). Thin-layer chromatography was used to separate triglycerides (TG), phospholipids (PL), cholesterol esters (CE), and free FA (FFA) in the extracted total plasma lipids as previously described (Dannenberger et al., 2017). After lipid class separation in a chromatography glass chamber, the thin-layer chromatography plates were dipped into a 0.03\% 2.7-dichlorofluorescein solution (Chromatogram Immersion Device III, CAMAG, Muttenz, Switzerland) for visualization of the lipid fractions under UV light. The lipid fractions were scraped off the plate and rinsed with chloroform/methanol (2:1, vol/vol). The obtained extracts were filtered and reduced to dryness under a gentle nitrogen stream for subsequent transesterification and gas chromatography measurements.

For analyses of FA in total plasma lipids and lipid fractions, a capillary gas chromatograph with a CP-Sil $88 \mathrm{CB}$ column $(100 \mathrm{~m} \times 0.25 \mathrm{~mm}$, Agilent, Santa Clara, CA) was used, which was installed in a PerkinElmer gas chromatograph CLARUS 680 (PerkinElmer Instru- ments, Shelton, CT) with a flame ionization detector and split injection. Details of the chromatography conditions were previously published by Dannenberger et al. (2012). Fatty acids were quantified using C19:0 as an internal standard. A reference standard mixture (Sigma FAME, Sigma-Aldrich, Deisenhofen, Germany) and methyl esters of C18:1 cis-11, C22:5n-3, C18:2 cis9,trans-11 (Matreya LLC, State College, PA), C22:4n -6 (Sigma-Aldrich), and C18:4n-3 (Larodan, Limhamn, Sweden) were used for calibration. The 5-point calibration was verified after analysis of 5 samples, and the results ranged between 16 and $415 \mu \mathrm{g} / \mathrm{mL}$.

Fatty acid percentages below the detection limit of $0.01 \%$ were defined as $10 \%$ of the detection limit for statistical analyses. The percentage of trans-10,cis-12 CLA in lipid fractions was below the detection limit. One sample (EFA group, d 5) was excluded from statistical analysis of the FA composition in lipid fractions due to technical reasons. To estimate the activity of $\Delta^{5}, \Delta^{6}$, and $\Delta^{9}$ desaturase, the desaturase indices were calculated as the ratio [product]: [precursor + product] (Kelsey et al., 2003; Nudda et al., 2008). To estimate the relationship between calf and maternal FA, data on the FA composition in maternal plasma and colostrum from d 1 were obtained from Vogel et al. (2020) and Gnott et al. (2020).

\section{Statistical Analyses}

Statistical analyses were performed with SAS for Windows (version 9.4, SAS Institute Inc., Cary, NC) using the MIXED procedure. Data for nutrient intake, plasma FA composition, and BW were analyzed using the MIXED procedure by repeated-measures ANOVA containing EFA (level: yes, no), CLA (level: yes, no), time (levels: day relative to calving), block (levels: 1 to 5), sex, and their respective interactions (EFA $\times$ $\mathrm{CLA}$; EFA $\times$ time; CLA $\times$ time; EFA $\times$ CLA $\times$ time) as fixed effects. For analyses of milk composition, the same model was used with the fixed effects EFA (level: yes, no), CLA (level: yes, no), milking number (levels: milking 1 to 9 after calving), block (levels: 1 to 5), and their respective interactions. The duration of maternal FA supplementation and gestation length were included as covariates. The REPEATED statement was utilized to consider measurements from the same calf or from milk from the same dam applying an unstructured covariance matrix for analyses of FA composition and BW. Milk composition was analyzed using a compound-symmetry covariance structure. Pairwise differences in least squares means (LSM) were analyzed by the Tukey-Kramer test. Partitioned analyses of the LSM for interactions were conducted with the SLICE statement of the MIXED procedure. The results are 
presented as LSM \pm SE unless otherwise stated. Effects were considered significant if $P<0.05$.

To analyze the relationship between FA percentages in maternal and calf plasma as well as colostrum and calf plasma, Spearman's rank-order correlations were applied using the CORR procedure of SAS.

\section{RESULTS}

\section{Milk Composition, Calf Performance, and Gestation Length}

The DM content in the first milking after calving on d 1 was lower $(P<0.01)$ for dams that received CLA than for dams in the CTRL group (Figure 1A). The DM content in the second milking on $\mathrm{d} 1$ was higher $(P<0.05)$ in dams receiving CLA than in dams in the EFA + CLA treatment. The protein concentration in the first milking on d 1 was lower $(P<0.05)$ in milk from dams supplemented with CLA than in that from dams that did not receive the CLA supplement (Figure 1B). The DM content and protein concentration in colostrum decreased $(P<0.01)$ from d 1 to 5 in all groups and were similar among groups from d 2 on. The fat concentration in milk variably changed with time $(P$ $<0.001$ ) during the first 5 DIM, showing the lowest concentration in the third milking and the highest concentration in the seventh milking (Figure 1C). The fat concentration was lower $(P<0.05)$ on d 1,2 (fourth milking), and 3 (fifth milking) in milk of dams receiving EFA than in milk from those receiving no EFA treatment. In the first milking after calving, the fat concentration was higher $(P<0.05)$ in CTRL than in both EFA-treated groups. On d 2 (fourth milking), the fat concentration was higher $(P<0.01)$ in CLA than in EFA+CLA. The lactose concentration increased $(P$ $<0.001$ ) from d 1 to 5 in all groups (Figure 1D). The lactose concentration was higher $(P<0.05)$ on $\mathrm{d} 1$ (2nd milking), d 3 (fifth milking), and d 4 (8th milking) in the milk of dams treated with EFA than in that from dams receiving no EFA treatment. In addition, the lactose concentration was higher $(P<0.05)$ on $\mathrm{d} 1$ (2nd milking) in EFA+CLA than in CLA cows and was higher $(P<0.05)$ on $\mathrm{d} 4$ (8th milking) in dams treated with EFA than in CTRL cows.

The protein and lactose intake did not differ among calves during the first $5 \mathrm{~d}$ of life, but fat and energy intake on $\mathrm{d} 1$ and 3 were lower $(P<0.05)$ in EFA- than in non-EFA-treated calves (Table 1$)$. The fat intake was higher $(P<0.05)$ on $d 1$ in CTRL than in EFA and was higher $(P<0.05)$ on $d 3$ in CLA than in EFA+CLA. Furthermore, energy intake on d 3 was higher $(P<$ 0.05) in CLA than EFA+CLA. Despite differences in energy intake, the BW on $\mathrm{d} 5$ as well as the birth weight
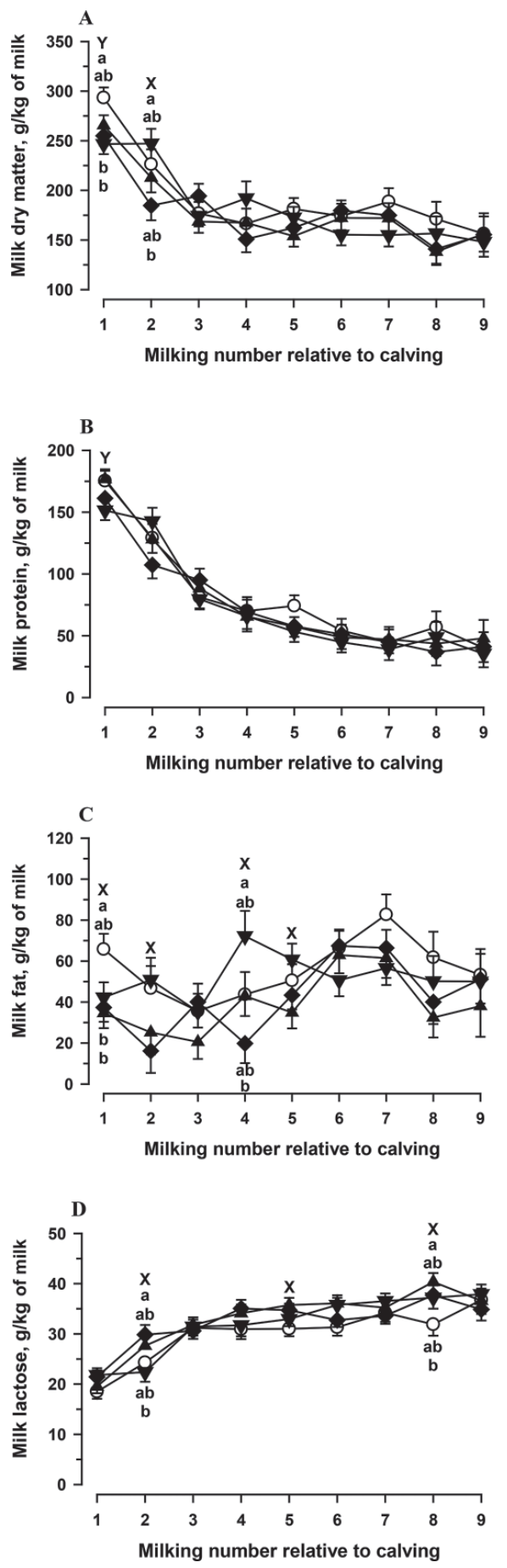

Figure 1. Effects of supplementation with coconut oil (O CTRL; $\mathrm{n}=9)$, linseed and safflower oil $(\boldsymbol{\Delta} \mathrm{EFA} ; \mathrm{n}=9)$, Lutalin (BASF SE, Ludwigshafen, Germany; $\nabla$ CLA; cis-9,trans-11 and trans-10, cis-12;

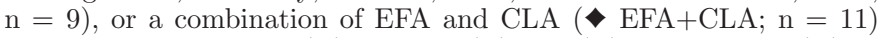
on the content of DM (A), protein (B), fat (C), and lactose (D) in fresh matter of milk from the first 9 milkings postpartum. Data are presented as LSM $\pm \mathrm{SE}$; different letters $(\mathrm{a}, \mathrm{b})$ indicate significant differences between groups; $\mathrm{X}$ indicates significant differences between EFA- and non-EFA-treated animals; Y indicates significant differences between CLA- and non-CLA-treated animals. The effect of EFA $\times$ time interaction on the milk lactose content and the effect of EFA on the milk fat content was significant $(P<0.05)$. 

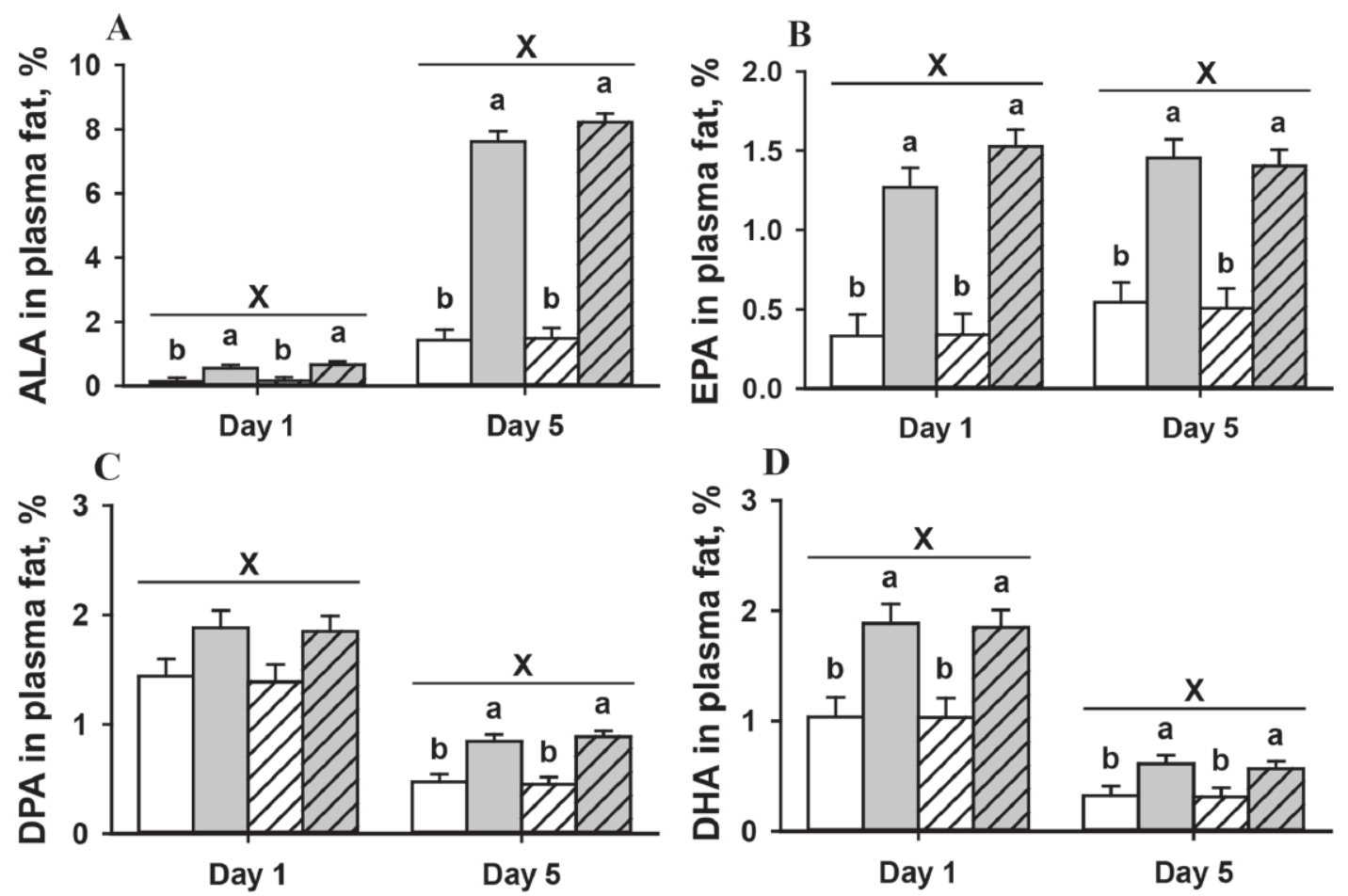

D
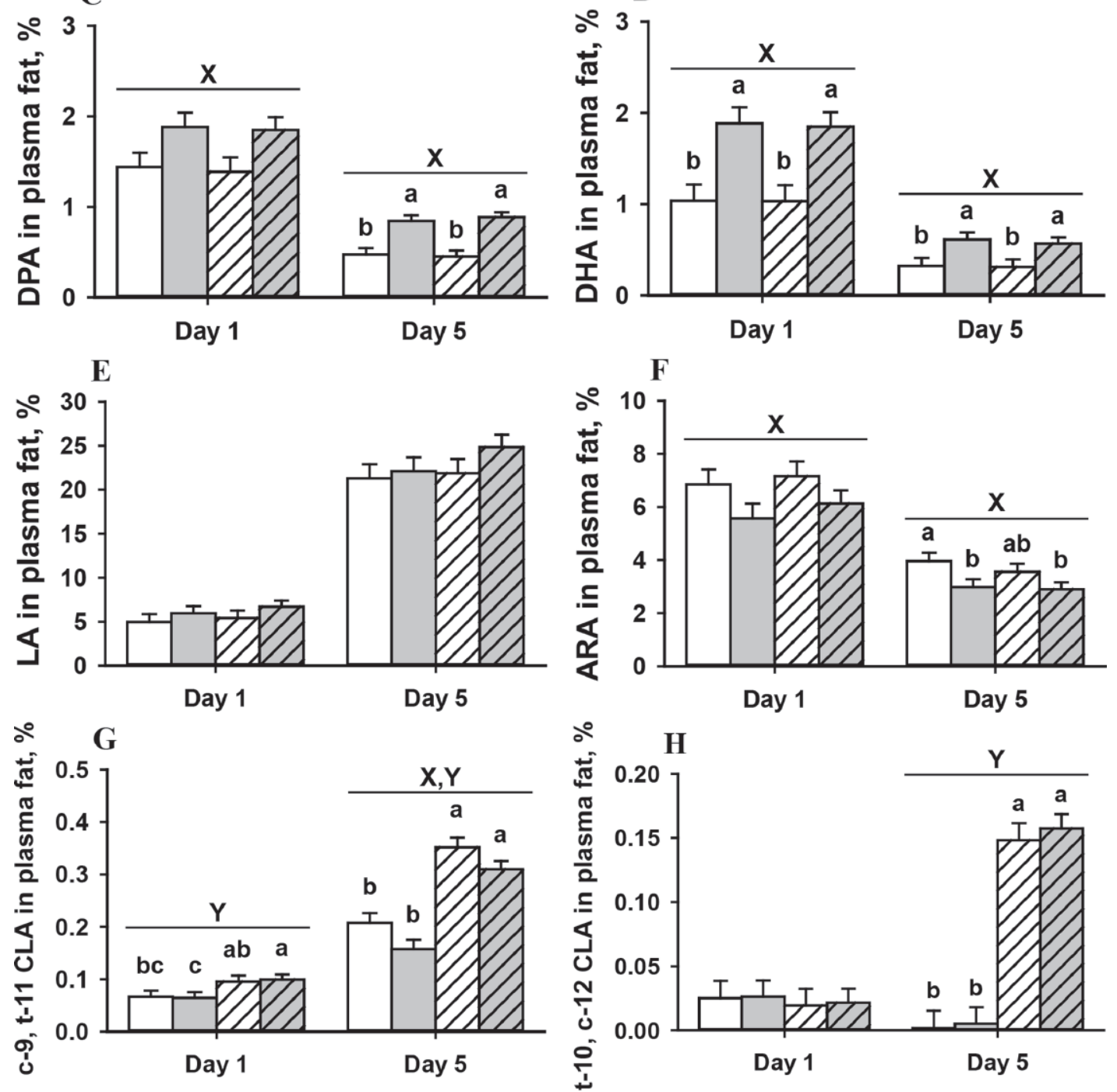

Figure 2. Effects of maternal supplementation with coconut oil (white bars; CTRL; $\mathrm{n}=9$ ), linseed and safflower oil (gray bars; EFA; $\mathrm{n}=9$ ), Lutalin (BASF SE, Ludwigshafen, Germany; striped white bars; CLA; cis-9,trans-11 and trans-10,cis-12; n = 9), or a combination of EFA and CLA (striped gray bars; EFA+CLA; $\mathrm{n}=11$ ) on the proportion of $\alpha$-linolenic acid (ALA; A), eicosapentaenoic acid (EPA; B), docosapentaenoic acid (DPA; C), docosahexaenoic acid (DHA; D), linoleic acid (LA; E), arachidonic acid (ARA; F), cis-9, trans-11 CLA (cis-9, trans-11 CLA; G), and trans-10,cis-12 CLA (trans-10,cis-12 CLA; H) in plasma of calves on d 1 and 5 of life. Data are presented as LSM \pm SE; different letters $(\mathrm{a}-\mathrm{c})$ indicate significant differences between groups; X indicates significant differences between EFA- and non-EFA-treated animals; Y indicates significant differences between CLA- and non-CLA-treated animals. A significant effect $(P<0.05)$ was observed for ALA (EFA, time, and EFA $\times$ time interaction), EPA (EFA and time), DPA (EFA and time), DHA (EFA, time, and EFA $\times$ time interaction), LA (time), ARA (EFA and time), cis-9, trans-11 CLA (EFA, CLA, time, EFA $\times$ time interaction, and CLA $\times$ time interaction), and trans-10, cis-12 CLA (CLA, time, and CLA $\times$ time interaction). 
Table 2. Relationship between the fatty acid composition in maternal and calf plasma fat on d 1 and colostrum and calf plasma on d 5 of life

\begin{tabular}{|c|c|c|c|c|}
\hline \multirow[b]{3}{*}{ Fatty acid $^{1}$} & \multicolumn{4}{|c|}{ Correlation } \\
\hline & \multicolumn{2}{|c|}{$\begin{array}{c}\text { Dam - Calf } \\
\quad(\mathrm{n}=38)\end{array}$} & \multicolumn{2}{|c|}{$\begin{array}{c}\text { Colostrum - } \text { Calf }^{3} \\
\quad(\mathrm{n}=38)\end{array}$} \\
\hline & $\mathrm{r}$ & $P$-value & $\mathrm{r}$ & $P$-value \\
\hline$\overline{\mathrm{ALA}}$ & 0.74 & $<0.001$ & 0.85 & $<0.001$ \\
\hline EPA & 0.77 & $<0.001$ & 0.79 & $<0.001$ \\
\hline DPA & 0.56 & $<0.001$ & 0.75 & $<0.001$ \\
\hline DHA & 0.65 & $<0.001$ & \multicolumn{2}{|c|}{ 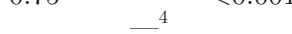 } \\
\hline LA & 0.12 & 0.49 & 0.36 & 0.03 \\
\hline ARA & 0.50 & $<0.01$ & 0.48 & $<0.01$ \\
\hline cis-9,trans-11 CLA & 0.55 & $<0.001$ & 0.37 & 0.02 \\
\hline trans-10, cis-12 CLA & $0.04^{5}$ & 0.82 & 0.40 & 0.01 \\
\hline
\end{tabular}

${ }^{1} \mathrm{ALA}=\alpha$-linolenic acid; EPA $=$ eicosapentaenoic acid; DPA $=$ docosapentaenoic acid; DHA = dosahexaenoic acid; $\mathrm{LA}=$ linoleic acid; ARA = arachidonic acid.

${ }^{2}$ Relationship between fatty acids in maternal plasma fat and fatty acids in plasma fat of calves at birth and before first colostrum intake. Data for fatty acids in the plasma fat of cows are shown in Supplemental Table S3 (https://doi.org/10.22000/360) and were first published by Gnott et al. (2020).

${ }^{3}$ Relationship between fatty acids in milk fat of first colostrum after calving and fatty acids in plasma fat of calves on d 5. Data for fatty acids in colostrum are shown in Supplemental Table S3 and were first published by Vogel et al. (2020).

${ }^{4}$ Not detected in colostrum.

${ }^{5} \mathrm{n}=37$.

were similar among groups (LSM $\pm \mathrm{SE}$ were $43.6 \pm 2.0$ $\mathrm{kg}$ for birth weight and $45.7 \pm 2.1 \mathrm{~kg}$ for BW on d 5). Accordingly, no difference was observed for ADG (LSM $\pm \mathrm{SE}$ was $0.51 \pm 0.05 \mathrm{~kg} / \mathrm{d}$ ). The weights of female and male calves were similar (data not shown).

Gestation time tended to increase if dams received EFA compared with that in dams without EFA supplementation $(P=0.07)$, with $278 \pm 2 \mathrm{~d}$ and $277 \pm 2$ $\mathrm{d}(\mathrm{SEM} \pm \mathrm{SE})$ in EFA and EFA+CLA and $274 \pm 2$ and $276 \pm 2 \mathrm{~d}$ in CTRL and CLA cows, respectively. Consequently, the supplementation period tended to be longer for dams receiving the EFA supplement than in those without EFA supplementation $(P=0.08)$, with supplementation times of $63.8 \pm 2.8$ and $63.2 \pm 2.3 \mathrm{~d}$ $(\mathrm{SEM} \pm \mathrm{SE})$ for EFA and EFA+CLA and $58.9 \pm 2.8$ and $61.0 \pm 2.8 \mathrm{~d}$ for CTRL and CLA cows, respectively.

\section{Fatty Acid Composition of Total Plasma Fat}

The plasma lipid content ranged between $0.06 \%$ and $0.08 \% \pm 0.01 \%$ at birth and was increased by $\mathrm{d} 5$ of life $(P<0.001)$, reaching $0.17 \%$ to $0.18 \% \pm 0.01 \%$ (Supplemental Table S1, https://doi.org/10.22000/ 360). Despite similar plasma lipid contents between the groups, the proportion of various FA in the plasma was affected by the maternal treatment (Figure 2; Supplemental Table S1).

Concentrations of all measured FA in plasma fat and in blood plasma are presented in Supplemental Tables S1 and S2 (https://doi.org/10.22000/360), respectively.
The concentration of ALA in plasma fat was higher $(P$ $<0.01$ ) immediately after birth and before first milk intake in calves of both EFA groups than in CLA and CTRL calves (Figure 2A). Plasma ALA increased $(P<$ 0.01 ) in all calves from d 1 to 5 , but the marked increase in ALA in EFA and EFA+CLA calves resulted in a much higher ALA concentration $(P<0.001)$ in calves from both EFA groups than in CTRL and CLA calves on d 5 of life. The concentration of eicosapentaenoic acid (EPA) in plasma fat increased $(P<0.01)$ only in non-EFA-supplemented calves, and the concentrations of docosapentaenoic acid (DPA) and docosahexaenoic acid (DHA) decreased $(P<0.001)$ in all groups from d 1 to 5 of life (Figure 2B-D). Concentrations of EPA and DHA as well as the sum of n-3 FA (Supplemental Table S1) were higher in plasma fat of EFA and EFA+CLA calves than in CTRL and CLA calves on d 1 and $5(P$ $<0.05)$; for DPA, a higher concentration in individual EFA groups was only determined on d $5(P<0.001)$, but there was also an EFA effect with higher DPA concentrations in EFA- than non-EFA-treated calves on d 1. Moreover, the concentrations of ALA, EPA, DPA, and DHA in calf plasma fat at birth were positively correlated with the concentration of the respective FA in maternal plasma fat (Supplemental Table S3, https: //doi.org/10.22000/360), with correlation coefficients ranging from 0.56 to 0.77 (Table 2). The proportions of ALA, EPA, and DPA in calf plasma fat on d 5 correlated with the concentration of these $\mathrm{FA}$ in the fat fraction of colostrum (Table 2). 
The concentrations of LA and total n- 6 FA in plasma fat were similar among groups, but arachidonic acid (ARA) was lower $(P<0.05)$ in calves from EFAthan non-EFA-treated dams on $\mathrm{d} 1$ and 5 (Figure 2E, 2F; Supplemental Table S1). The concentration of LA increased $(P<0.001)$, but the concentration of ARA decreased $(P<0.001)$ from d 1 to 5 in all groups. On d 5 , the concentration of ARA in plasma fat was higher $(P<0.05)$ in CTRL than in EFA and EFA+CLA. There was no relationship between the percentage of LA in plasma fat of dams and calves on d 1 (Table 2). Nevertheless, the proportions of ARA in the plasma fat of newborn calves were related to those measured in their dams (Table 2). In addition, the concentrations of LA and ARA in milk fat were positively related to FA concentrations in calf plasma fat on d 5 (Table 2).

Prepartum supplementation of cows with CLA affected the cis-9,trans-11 CLA in the plasma fat of newborn unsuckled calves on d $1(P<0.001$; Figure $2 \mathrm{G})$. The concentration was higher $(P<0.05)$ in EFA+CLA than in CTRL and EFA and was higher $(P<0.05)$ in CLA than EFA. The concentration of cis-9,trans-11 CLA increased $(P<0.001)$ in all groups from $\mathrm{d} 1$ to 5 , was higher $(P<0.001)$ on d 5 in calves from CLAthan non-CLA-treated dams, and was lower $(P<0.05)$ in calves from EFA- than non-EFA-treated dams. The concentration of trans-10, cis-12 CLA in plasma fat was similar among groups at birth, increased $(P<0.001)$ in calves from cows supplemented with CLA, but decreased $(P<0.05)$ in calves from non-CLA-supplemented dams, and was higher $(P<0.001)$ on $\mathrm{d} 5$ in calves from CLA-treated dams than non-CLA-treated dams (Figure $2 \mathrm{H}$ ). The concentration of cis-9,trans-11 CLA in calf plasma fat on d 1 was positively related to the concentration in maternal plasma fat (Table 2). Furthermore, positive correlations for both CLA isomers existed between colostrum fat and calf plasma fat on d 5 (Table 2).

On $\mathrm{d} 1$, the $\Delta^{5}$ desaturase index was higher in CTRL and CLA than in EFA and in EFA+CLA ( $P$ $<0.01$; Supplemental Table S1). However, in EFA and EFA+CLA, the desaturase index increased $(P<0.001)$ from d 1 to 5 , resulting in similar $\Delta^{5}$ desaturase indices between groups on $\mathrm{d} 5$. In contrast, the $\Delta^{6}$ desaturase index was similar between groups on $\mathrm{d} 1$, decreased $(P$ $<0.001)$ from $\mathrm{d} 1$ to 5 in all groups and was higher $(P$ $<0.01)$ in CTRL than in EFA+CLA on $\mathrm{d} 5$. The $\Delta^{9}$ desaturase index was similar between groups on $\mathrm{d} 1$ but decreased $(P<0.01)$ only in EFA and EFA+CLA from d 1 to 5 . On d 5 , the $\Delta^{9}$ desaturase index was highest $(P<0.01)$ in CTRL and higher $(P<0.05)$ in CLA than in EFA+CLA.

\section{Fatty Acid Composition of Plasma Lipid Fractions}

Maternal treatments did not affect the proportion of TG, PL, CE, or FFA in total plasma lipids (Table $3)$. The largest lipid fraction in plasma was CE, and the other 3 fractions were present at comparable levels. The TG fraction increased $(P<0.05)$ and the FFA fraction decreased $(P<0.001)$ in plasma from d 1 to 5 of life in all groups, whereas the CE and PL fractions indicated an inconsistent pattern over time during the first $5 \mathrm{~d}$ of life.

The concentrations of all measured FA in TG, PL, CE, and FFA are presented in Supplemental Tables S4 to S7 (https://doi.org/10.22000/360). The concentration of ALA increased $(P<0.001)$ from d 1 to 5 and was higher $(P<0.001)$ on $\mathrm{d} 5$ in all lipid fractions except for FFA in calves from EFA-supplemented cows compared with calves from cows receiving no EFA treatment (Figures 3A, 4A, 5A, and 6A). The concentration of EPA was higher $(P<0.05)$ on $\mathrm{d} 1$ of life in the CE of calves from EFA- than non-EFA-treated dams. The concentration of EPA increased $(P<0.05)$ in the PL of calves from EFA-treated dams, in the CE of all calves, and in the TG of EFA+CLA calves and was higher $(P<0.01)$ in all lipid fractions except FFA in EFA- than in non-EFA-treated calves (Figures 3B, $4 \mathrm{~B}, 5 \mathrm{~B}$, and $6 \mathrm{~B})$. Concentrations of DPA and DHA were higher $(P<0.05)$ on $\mathrm{d} 1$ of life in the PL of calves from EFA- than non-EFA-treated dams (Figure 4C and $4 \mathrm{D})$. Concentrations of DPA and DHA decreased $(P<$ $0.05)$ in TG, PL, and $\mathrm{CE}$ but increased $(P<0.05)$ in FFA from $d 1$ to 5 of life and in PL were higher $(P<$ $0.05)$ on $\mathrm{d} 5$ in calves from EFA- than in calves from non-EFA-treated dams (Figures 3C, 3D, 4C, 4D, 5C, $5 \mathrm{D}, 6 \mathrm{C}$, and $6 \mathrm{D})$.

The concentration of LA increased $(P<0.001)$ in all lipid fractions in plasma from d 1 to 5 of life but was only higher $(P<0.05)$ on $\mathrm{d} 5$ in the PL of EFA- than non-EFA-treated calves (Figures $3 \mathrm{E}, 4 \mathrm{E}, 5 \mathrm{E}$, and $6 \mathrm{E}$ ). The concentration of ARA decreased $(P<0.01)$ in all lipid fractions except FFA from d 1 to 5 of life and was lower $(P<0.05)$ in PL on $\mathrm{d} 1$ and 5 and in $\mathrm{CE}$ on $\mathrm{d} 5$ in calves from EFA- than in calves from non-EFA-treated dams (Figure 3F, 4F, 5F, and 6F). Concerning CLA isomers, only cis-9,trans-11 CLA could be detected in lipid fractions (Figure 3G, 4G, 5G, and 6G). The concentration of cis-9,trans-11 CLA increased $(P<0.01)$ in TG, PL, and FFA from d 1 to 5 and was higher $(P$ $<0.05)$ on $\mathrm{d} 5$ in TG of CLA than in CTRL and EFA, in CE in CLA than in CTRL and EFA+CLA, and in PL in calves for CLA- than in calves from non-CLAtreated dams. In FFA, cis-9,trans-11 CLA was higher $(P<0.05)$ in CTRL than in EFA on d 1 of life. 


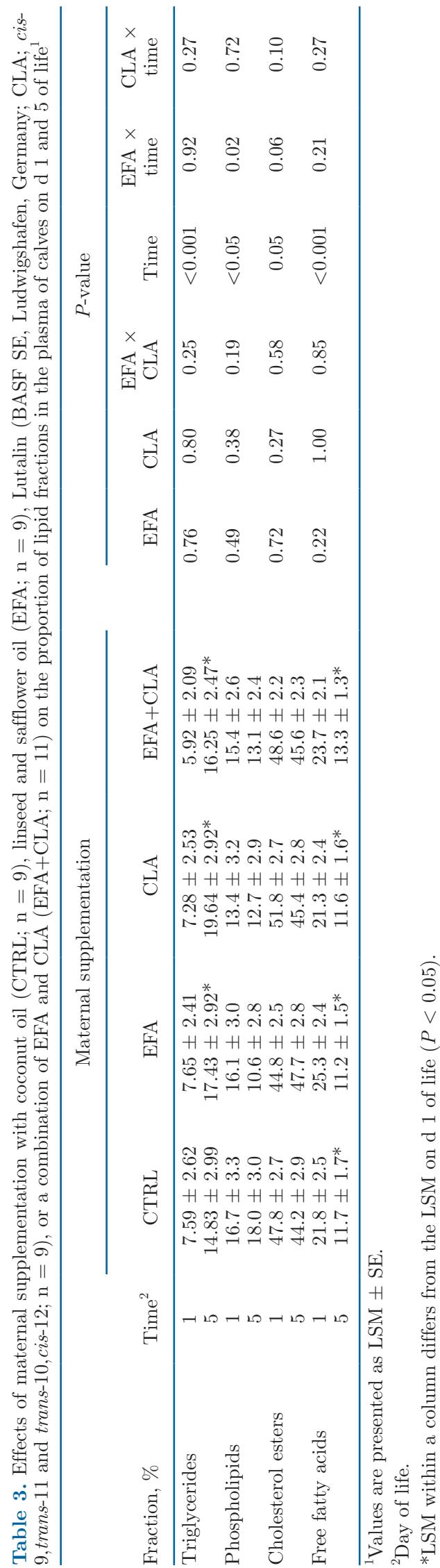

Plasma FA compositions were mostly similar between female and male calves (data not shown). Only the concentration of eicosatrienoic acid (20:3 cis-11, cis14,cis-17, n-3) was lower $(P<0.01)$ in female than male calves $(0.00 \pm 0.00$ vs. $0.03 \pm 0.01 \%$ for female and male calves, respectively).

\section{DISCUSSION}

The study has investigated the perinatal FA status in calves by changing maternal EFA and CLA supply starting in late pregnancy and continuing to the colostrum and transition milk period. Since maternal EFA and CLA treatments were performed by abomasal infusion of the dams, no rumen degradation of the supplied FA occurred (Vogel et al., 2020). The study revealed the importance of colostral and transition milk transfer of ALA and LA to their offspring but in addition pointed at a significant placental transfer of n-3 and n- 6 FA metabolites to the fetus.

\section{Effects on Gestation Length, Colostrum and Transition Milk Chemical Composition, and Calf Performance}

The results of the present study indicate an effect of maternal FA supply on colostrum composition. The lower DM content in colostrum from the first milking after calving of CLA-treated cows than that of non-CLA-treated cows was probably a consequence of a lower protein concentration in the colostrum of CLA-treated cows. In a recent study, a comparable CLA treatment resulted in a lower milk protein concentration in mid- to late-lactating dairy cows, and a repartitioning of body protein by the CLA treatment was discussed (Haubold et al., 2020). However, it is not yet known whether CLA treatment affects milk protein synthesis at the beginning of lactation. Many proteins in colostrum, such as immunoglobulins and growth factors, are stored, but not synthesized, by the mammary gland during the dry period (Grosvenor et al., 1993; Baumrucker and Bruckmaier, 2014). Therefore, a CLA effect on systemic whole body protein synthesis cannot be excluded. However, the lower protein concentration in colostrum from the first milking in the present study did not result from a reduced IgG concentration because the $\operatorname{IgG}_{1}$ and $\operatorname{IgG}_{2}$ concentrations in the first colostrum did not differ among treatment groups $[\mathrm{K}$. L. Uken, T. Stefaniak (Wroclaw University of Environmental and Life Science, Poland), and H. M. Hammon, unpublished observation].

Interestingly, EFA treatment increased the lactose concentration but decreased the fat concentration in milk from several milkings after calving, leading 

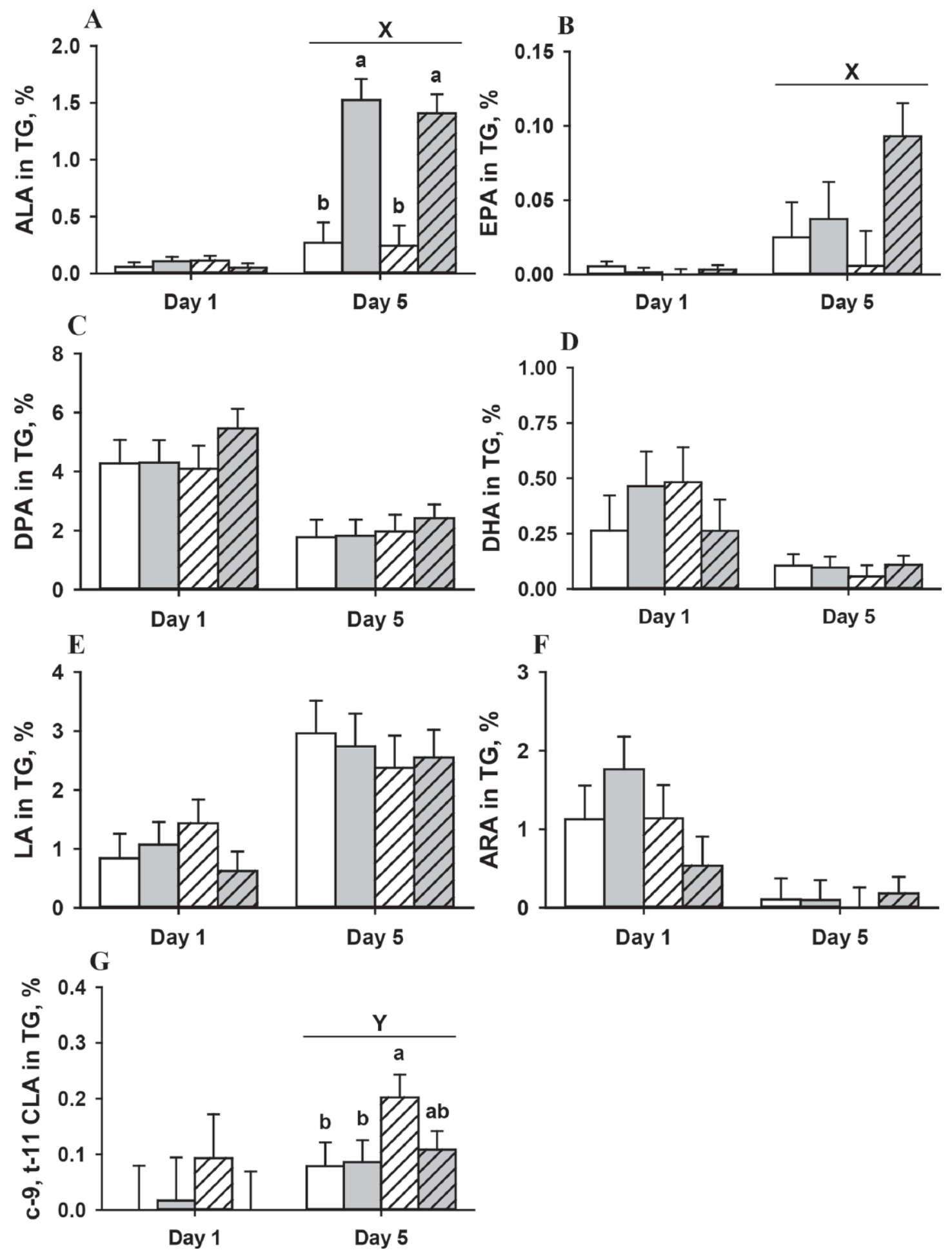

Figure 3. Effects of maternal supplementation with coconut oil (white bars; CTRL; $n=9$ ), linseed and safflower oil (gray bars; EFA; $\mathrm{n}=9$ ), Lutalin (BASF SE, Ludwigshafen, Germany; striped white bars; CLA; cis-9,trans-11 and trans-10,cis-12; n = 9), or a combination of EFA and CLA (striped gray bars; EFA+CLA; $\mathrm{n}=11$ ) on the proportion of $\alpha$-linolenic acid (ALA; A), eicosapentaenoic acid (EPA; B), docosapentaenoic acid (DPA; C), docosahexaenoic acid (DHA; D), linoleic acid (LA; E), arachidonic acid (ARA; F), and cis-9, trans-11 CLA (cis-9, trans-11 CLA; $\mathrm{G}$ ) in plasma triglycerides (TG) of calves on d 1 and 5 of life. Data are presented as LSM \pm SE; different letters (a, b) indicate significant differences between groups; $\mathrm{X}$ indicates significant differences between EFA- and non-EFA-treated animals; Y indicates significant differences between CLA- and non-CLA-treated animals. The negative LSM values generated for cis-9,trans-11 CLA in groups CTRL and EFA+CLA on $\mathrm{d} 1$ and for ARA in group CLA on d 5 were replaced by zero. A significant effect $(P<0.05)$ was observed for ALA (EFA, time, and EFA $\times$ time interaction), EPA (time and EFA $\times$ time interaction), DPA (time), DHA (time), LA (time), ARA (time), and cis-9, trans-11 CLA (time). 

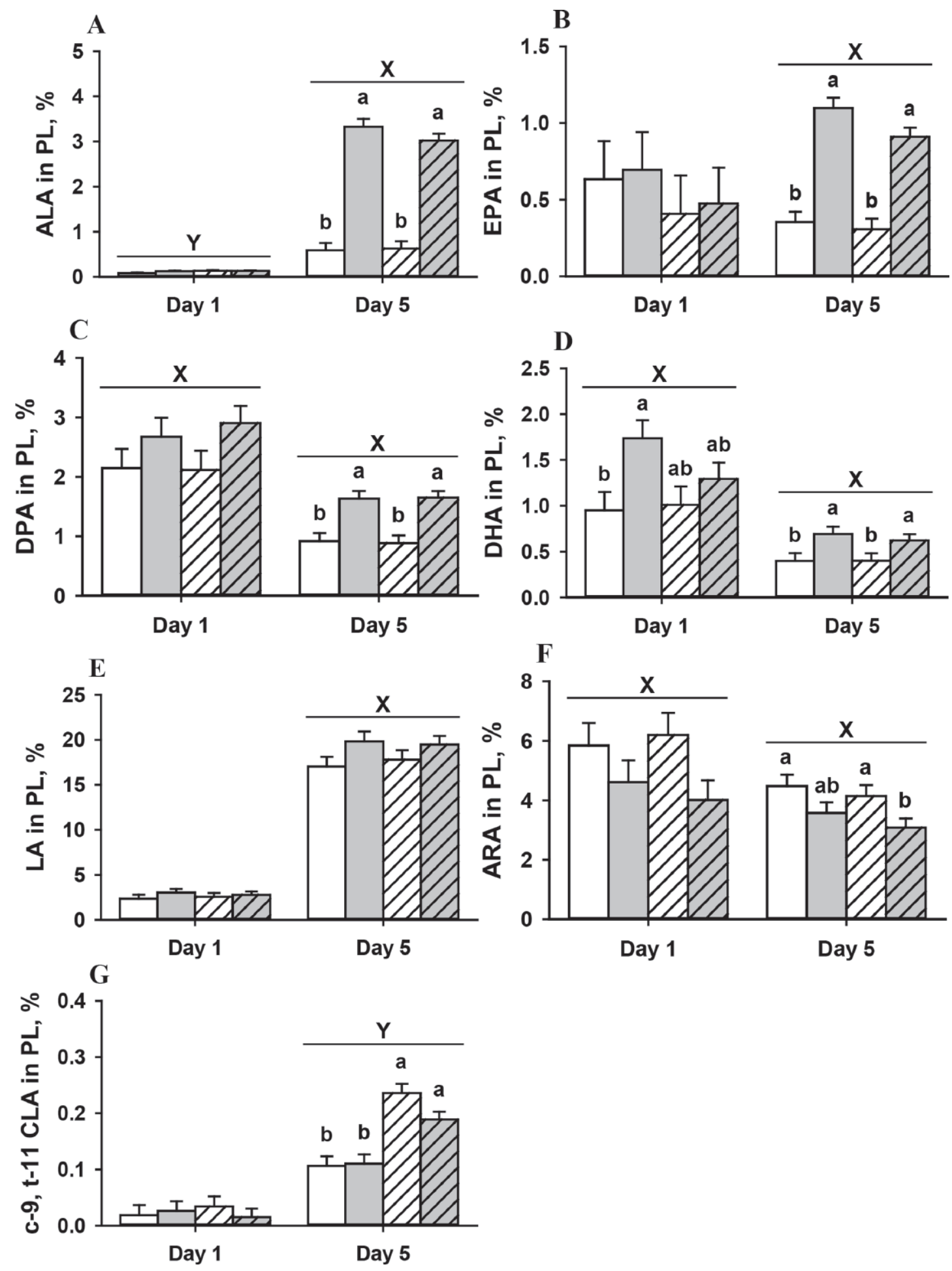

Figure 4. Effects of maternal supplementation with coconut oil (white bars; CTRL; $n=9$ ), linseed and safflower oil (gray bars; EFA; $\mathrm{n}=9$ ), Lutalin (BASF SE, Ludwigshafen, Germany; striped white bars; CLA; cis-9,trans-11 and trans-10, cis-12; n = 9), or a combination of EFA and CLA (striped gray bars; EFA+CLA; $\mathrm{n}=11$ ) on the proportion of $\alpha$-linolenic acid (ALA; A), eicosapentaenoic acid (EPA; B), docosapentaenoic acid (DPA; C), docosahexaenoic acid (DHA; D), linoleic acid (LA; E), arachidonic acid (ARA; F), and cis-9, trans-11 CLA (cis-9, trans-11 CLA; $\mathrm{G}$ ) in plasma phospholipids (PL) of calves on d 1 and 5 of life. Data are presented as LSM \pm SE; different letters (a, b) indicate significant differences between groups; X indicates significant differences between EFA- and non-EFA-treated animals; Y indicates significant differences between CLA- and non-CLA-treated animals. A significant effect $(P<0.05)$ was observed for ALA (EFA, time, and EFA $\times$ time interaction), EPA (EFA, and EFA $\times$ time interaction), DPA (EFA and time), DHA (EFA and time), LA (EFA and time), ARA (EFA and time), and cis9,trans-11 CLA (CLA, EFA $\times$ CLA interaction, time, and CLA $\times$ time interaction). 

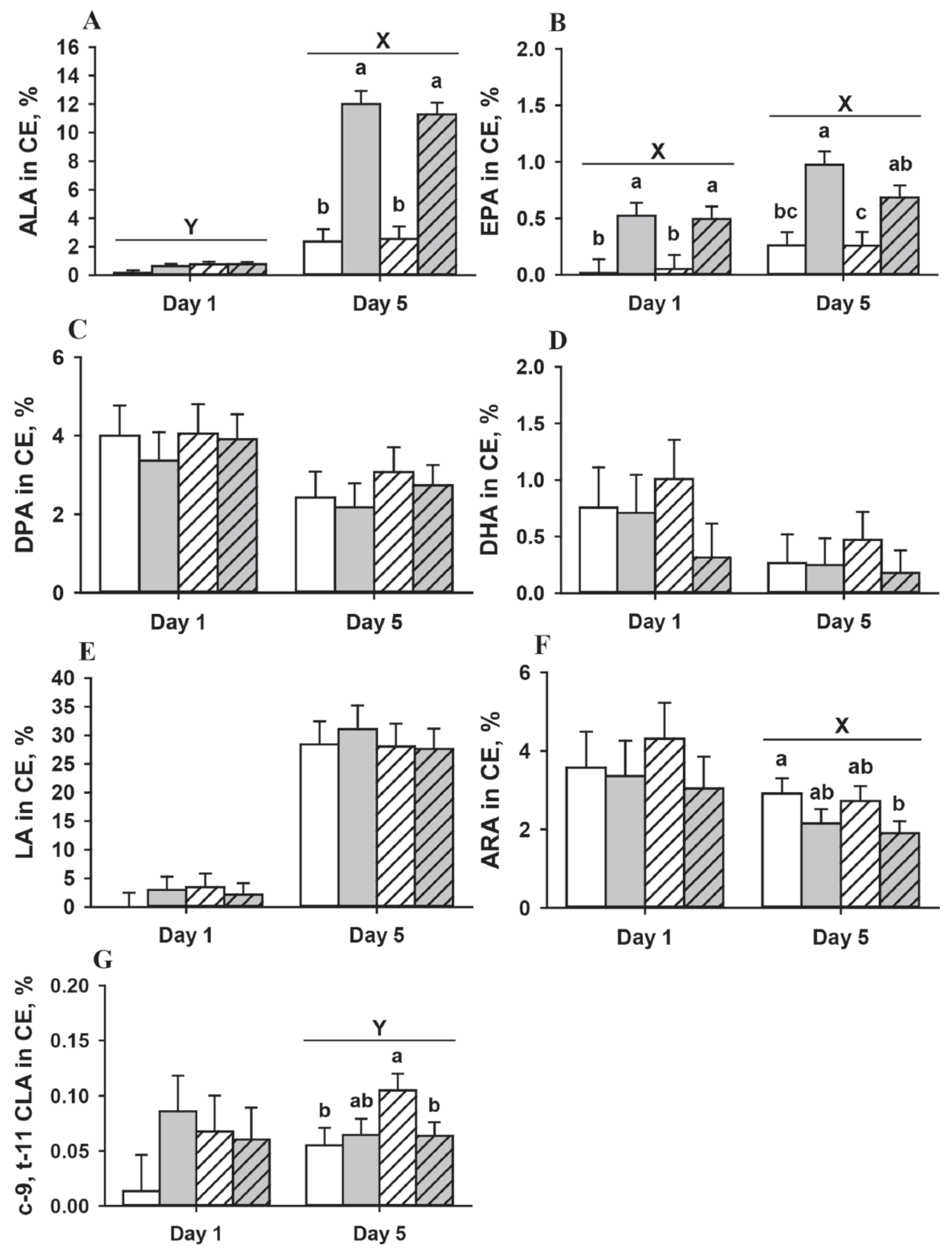

Figure 5. Effects of maternal supplementation with coconut oil (white bars; CTRL; $n=9$ ), linseed and safflower oil (gray bars; EFA; $\mathrm{n}=9$ ), Lutalin (BASF SE, Ludwigshafen, Germany; striped white bars; CLA; cis-9,trans-11 and trans-10, cis-12; n = 9), or a combination of EFA and CLA (striped gray bars; EFA+CLA; $\mathrm{n}=11$ ) on the proportion of $\alpha$-linolenic acid (ALA; A), eicosapentaenoic acid (EPA; B), docosapentaenoic acid (DPA; C), docosahexaenoic acid (DHA; D), linoleic acid (LA; E), arachidonic acid (ARA; F), and cis-9, trans-11 CLA (cis-9, trans-11 CLA; $\mathrm{G}$ ) in plasma cholesterol esters (CE) of calves on d 1 and 5 of life. Data are presented as LSM \pm SE; different letters (a, b) indicate significant differences between groups; X indicates significant differences between EFA- and non-EFA-treated animals; Y indicates significant differences between CLA- and non-CLA-treated animals. The negative LSM value generated for LA in group CTRL on d 1 was replaced by zero. A significant effect $(P<0.05)$ was observed for ALA (EFA, time, and EFA $\times$ time interaction), EPA (EFA and time), DPA (time), DHA (time), LA (time), and ARA (time). 
A

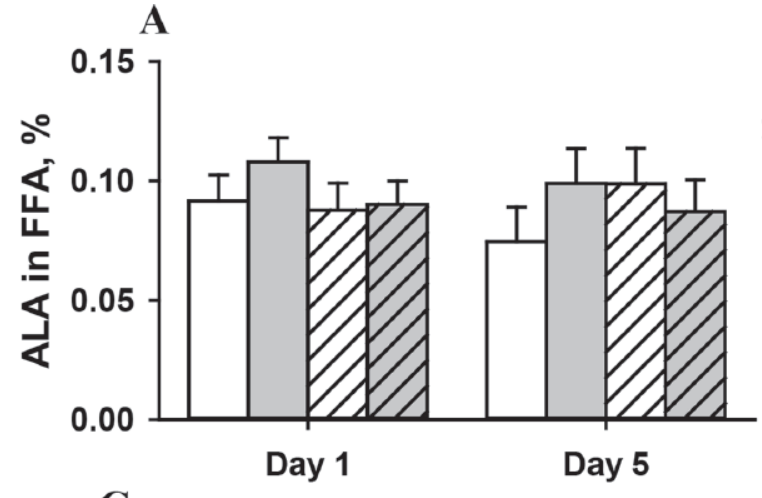

C

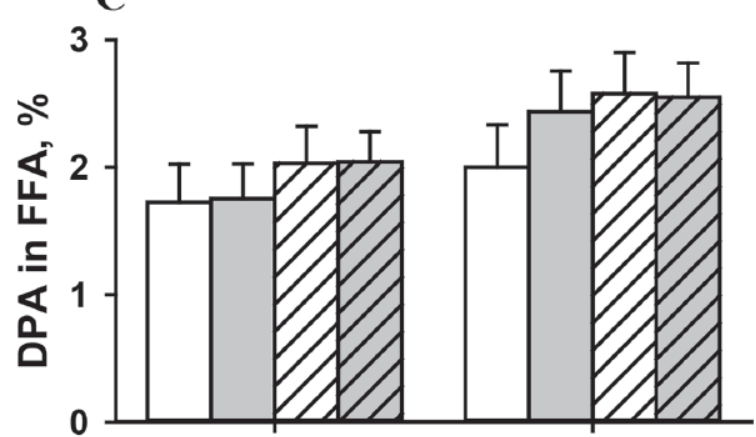

Day 1
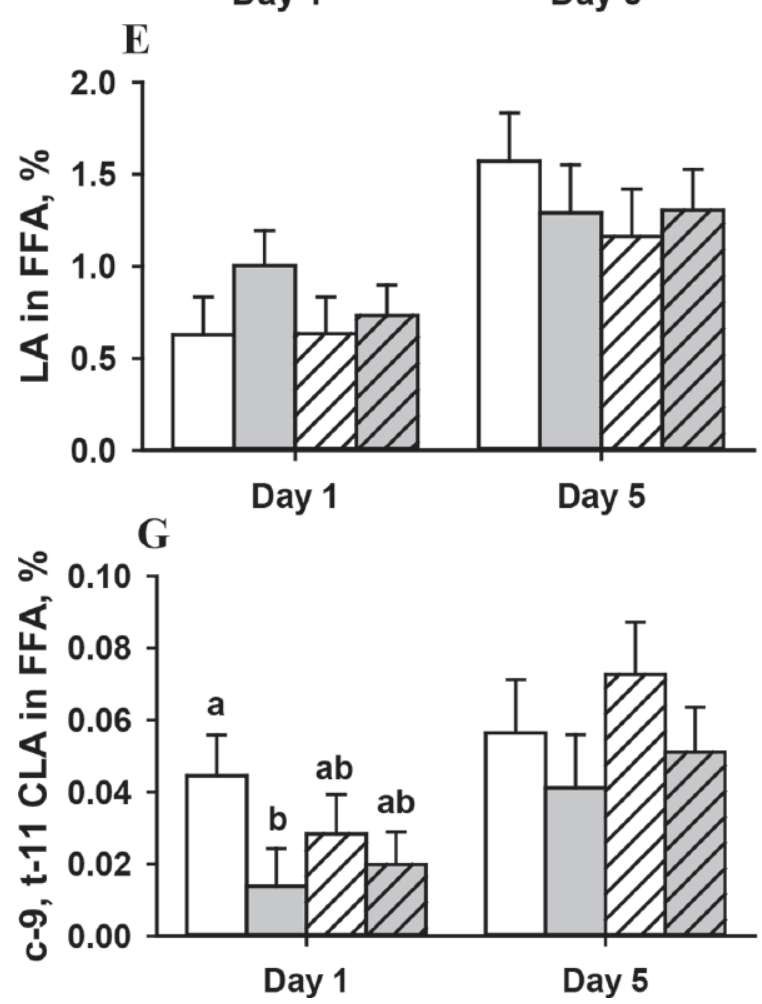

B

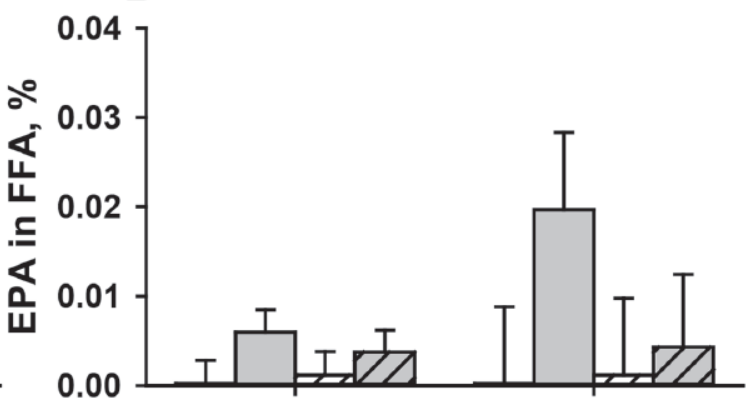

Day 1

Day 5

D

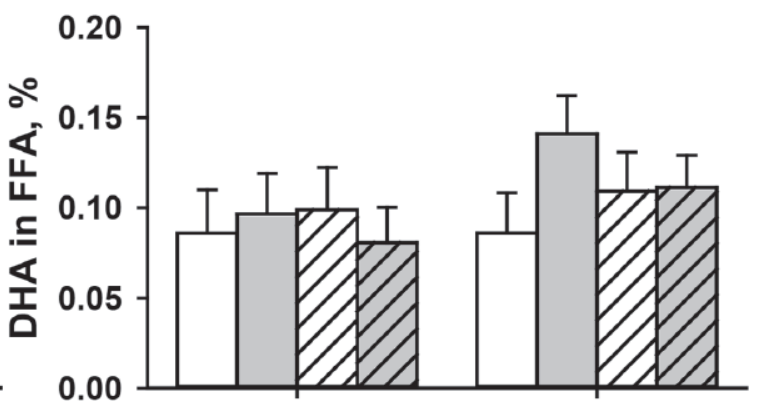

Day 1

Day 5

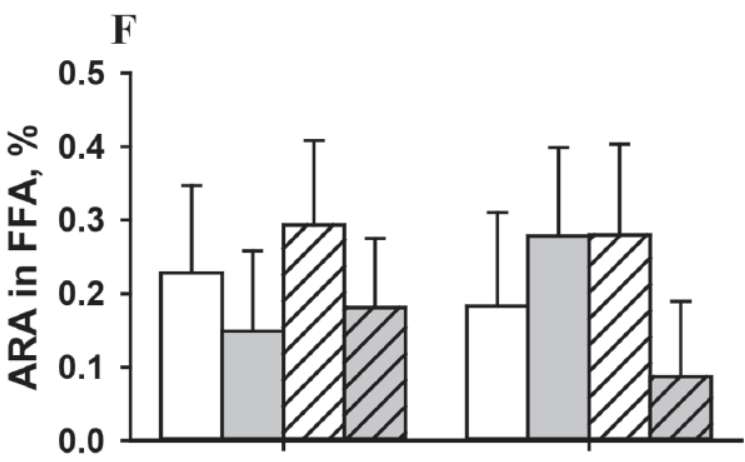

Day 1

Day 5

Figure 6. Effects of maternal supplementation with coconut oil (white bars; CTRL; n = 9), linseed and safflower oil (gray bars; EFA; $\mathrm{n}=9$ ), Lutalin (BASF SE, Ludwigshafen, Germany; striped white bars; CLA; cis-9,trans-11 and trans-10,cis-12; n = 9), or a combination of EFA and CLA (striped gray bars; EFA+CLA; $\mathrm{n}=11$ ) on the proportion of $\alpha$-linolenic acid (ALA; A), eicosapentaenoic acid (EPA; B), docosapentaenoic acid (DPA; C), docosahexaenoic acid (DHA; D), linoleic acid (LA; E), arachidonic acid (ARA; F), and cis-9,trans-11 CLA (cis-9,trans-11 CLA; $\mathrm{G}$ ) in plasma free fatty acids (FFA) of calves on d 1 and 5 of life. Data are presented as LSM \pm SE; different letters (a, b) indicate significant

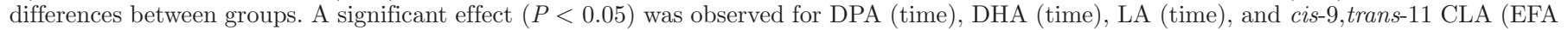
and time). 
to lower fat concentrations in the colostrum of EFAsupplemented cows. A reduced milk fat content was repeatedly observed in previous studies when cows received linseed products. However, in those studies, milk fat depression was presumably caused by the formation of trans FA from ruminal biohydrogenation of EFA (Shingfield et al., 2010; Moallem, 2018). We applied EFA directly into the abomasum to prevent ruminal biohydrogenation. Thus, a reduced de novo FA synthesis in the mammary gland, indicated by a lower proportion of middle-chain FA in the first colostrum (Vogel et al., 2020), was the result of a greater availability of preformed FA by EFA infusion. The reduced de novo FA synthesis in the mammary gland due to EFA infusion was obviously responsible for the observed milk fat decrease in the mammary tissue of EFA-treated cows, as previously indicated in cows supplemented with linseeds or canola oil (Chelikani et al., 2004; Lerch et al., 2015). The decrease in milk fat under the EFA treatment was not associated with treatment effects on DMI or the plasma nonesterified FA concentration in cows around calving (Vogel et al., 2020), indicating that the increased availability of long-chain FA by the EFA infusion per se was sufficient to inhibit de novo FA synthesis and reduce the milk fat concentration.

Supplementation with CLA did not reduce milk fat during the first milkings after calving. A significant milk fat reduction by CLA treatment in these cows was observed during late lactation and again after calving at the end of the first week, although the CLA treatment comprised infusion from wk 9 before calving without interruption but with half the dose during the dry period (Vogel et al., 2020). The diminishing effect of CLA treatment on milk fat depression immediately after calving is well known from the literature (Castañeda-Gutiérrez et al., 2005; Odens et al., 2007; Hötger et al., 2013). Since CLA primarily inhibits de novo FA synthesis, which is already reduced immediately after birth due to low feed intake and limited acetate availability, the milk fat decrease with the CLA treatment during the first days after calving was less effective.

The availability of fat and energy on $\mathrm{d} 1$ and 3 of life was lower for calves whose dams received the EFA treatment. In addition, maternal EFA supplementation seemed to prolong gestation, as indicated by a trend toward longer gestation length for EFA-supplemented cows. Prolonging effects of n-3 FA on gestation were repeatedly described in the literature and are associated with increased EPA availability that leads to a lower synthesis of series-2 prostaglandins (Olsen et al., 1992; Abayasekara and Wathes, 1999; Pickard et al., 2008). Although maternal FA supplementation partly modulated gestation time and nutrient availability from colostrum and transition milk, maternal FA supple- mentation did not affect birth weight or body growth until d 5 of life. The experimental period in the current study was too short to estimate growth effects in calves. Nevertheless, there might be effects on the postnatal growth regulation by the somatotropic axis in these calves. At least, the CLA and EFA+CLA treatments affected parameters of the somatotropic axis in dairy cows during the transition period (Vogel et al., 2021). Feeding goats or ewes variable amounts of n-3 FA during late gestation had no effect on the birth weight of the offspring in previous studies (Duvaux-Ponter et al., 2008; Coleman et al., 2018; Nickles et al., 2019). Nevertheless, there are indications that ADG can be improved when calves are fed increased quantities of ALA alone or both ALA and LA (Hill et al., 2009; Garcia et al., 2014b). However, calves in those studies were only investigated during the first $30 \mathrm{~d}$ of life. Thus, a longer observation period might be required to evaluate whether an elevated maternal EFA supply by milk can improve growth performance.

\section{Effects on FA Profiles in Blood Plasma Immediately After Birth}

Providing supplementation of EFA containing high amounts of ALA to dams during late gestation increased ALA concentration in plasma fat of cows 4.5fold $(2.29 \pm 0.41 \%$ and $10.20 \pm 0.41 \%$ for CTRL and EFA cows, respectively, at d 42 before calving; Gnott et al., 2020). The increase of plasma ALA corresponded to changes of ALA in milk fat when cows were on pasture with fresh grass instead of receiving a corn silage-based TMR (Kelly et al., 1998; Kay et al., 2005; Couvreur et al., 2006). As a consequence of maternal ALA supplementation during late gestation in the present study, there was a slight increase of plasma ALA concentration in calves before first colostrum intake. However, EFA supplementation to the dams barely caused significant changes in ALA concentrations in individual plasma lipid fractions of the calves directly after birth. This illustrates the low transfer of ALA through the placenta to the bovine fetus. This finding supports previous investigations on the transfer of ALA from the mother to the fetus during late gestation, although the treatment times and concentrations of ALA were slightly different (Moallem and Zachut, 2012).

Even though the treatment effect of maternal EFA supply on fetal ALA concentration was low, the maternal EFA supply resulted in elevated proportions of EPA and DHA in plasma fat of EFA and EFA+CLA calves at birth. The n-3 metabolites were especially increased in the CE fraction (EPA) and PL fraction (DHA) of the blood plasma. In ruminants, most of the PUFA in plasma are localized in the $\mathrm{CE}$ and PL 
fractions (Christie, 1981; Innis, 2005; Palmquist, 2010). Fetal n-3 synthesis by elongation and desaturation of ALA cannot be excluded (Shand et al., 1978; Elmes et al., 2004), but the present study suggests that the n-3 FA metabolites in fetal blood most likely resulted from the dam through placental transfer. All measured n-3 FA increased in maternal blood plasma after EFA or EFA+CLA treatment, and plasma concentrations of EPA, DPA, and DHA were elevated in EFA-supplemented dams during late gestation and around calving, as shown in Supplemental Table S3 and illustrated in more detail by Gnott et al. (2020). $\alpha$-Linolenic acid can serve as a precursor for the synthesis of n-3 FA metabolites in the placenta, which possesses significant desaturase activity in ruminants (Duvaux-Ponter et al., 2008; Garcia et al., 2014a). In addition, the enrichment of DHA in plasma fat of the calves immediately after birth was approximately 8-fold higher than in plasma fat of their dams, especially when comparing calves and cows of the EFA treatment (Gnott et al., 2020). Even though placental transfer of PUFA is low, an increased proportion of DHA but not ALA in the plasma fat of newborn calves was already observed by Moallem and Zachut (2012). A selective transfer of DHA by the placenta was also reported in humans (Haggarty, 2002; Herrera, 2002; Hanebutt et al., 2008). Our results suggest that a similar mechanism must be active in the bovine placenta for DHA to be enriched in the fetal plasma fat, although histological compositions of human and bovine placentas differ greatly. On the other hand, plasma desaturase indices were low in calf plasma fat immediately after birth, which may indicate that DHA synthesis was not elevated by the fetus.

Numerous studies have indicated that LA can pass the ruminant placenta as well (Noble et al., 1978a; Garcia et al., 2014a; Salehi and Ambrose, 2017). The proportion of LA in plasma fat in the calves before first colostrum feeding was lower than that in the dams, but the ARA concentration was higher in the plasma fat of the calves than of the dams at calving. This finding is consistent with results on DHA supply, as discussed above, and placental n-6 FA transport in fetal sheep (Noble et al., 1982). Interestingly, there was only a numerically lower ARA concentration in the neonatal plasma fat after EFA treatment, even though the maternal ARA proportion in plasma fat and the neonatal $\Delta^{5}$ desaturase index were lower due to EFA treatment. Whether the reduction of the LA/ALA ratio by EFA supplementation affects $\Delta^{5}$ desaturase activity and impairs the synthesis and transfer of n- 6 FA derivatives in the bovine fetus is not yet known; however, a reduction of the LA/ALA ratio in the diet seems to lead to a preferential desaturation of n-3 instead of n- 6 FA in the livers of rats (Geiger et al., 1993).
The supply of cis-9,trans-11 CLA of the fetal calf may be enhanced if dams receive this CLA isomer, as suggested by the higher percentages of cis-9,trans-11 CLA in plasma fat of calves from CLA-treated dams directly after birth. However, the low correlation between cis-9,trans-11 CLA percentages in dam and calf plasma might indicate a more limited placental transfer of cis-9,trans-11 CLA than of ALA. Accordingly, Dänicke et al. (2012) found only a trend toward higher percentages of cis-9,trans-11 CLA in erythrocyte lipids of calves, whose dams received a supplement containing cis-9,trans-11 CLA during early gestation. Moreover, the authors did not detect trans-10,cis-12 CLA in the erythrocyte lipids of calves, which was also supplemented during early gestation (Dänicke et al., 2012). In the present study, trans-10,cis-12 CLA was not enhanced in calves at birth after maternal trans10,cis-12 CLA treatment during late gestation. It is unclear why maternal supplementation with the trans10,cis-12 isomer failed to increase its proportion in the plasma fat of neonatal calves. The lack of a relationship between the percentage of this isomer in maternal and neonatal plasma fat at birth might indicate that an altered maternal trans-10,cis-12 CLA status was not transferred to the fetus via the placenta.

\section{Effects on FA Profiles in Blood Plasma After Milk Feeding}

Supplementation of ALA by the EFA treatment resulted in a 19-fold increase of ALA in colostrum fat of EFA-cows when compared with CTRL cows $(0.07 \pm$ $0.11 \%$ and $1.34 \pm 0.10 \%$ for CTRL and EFA, respectively; Supplemental Table S3; Vogel et al., 2020). Concentration of ALA in colostrum fat was slightly higher than in milk fat of cow fed fresh grass or on pasture (ALA in milk fat: 0.7-1.12\%; Kelly et al., 1998; Kay et al., 2005; Couvreur et al., 2006), but in a recent study a greater EFA content in colostrum than mature milk in dairy cows was shown (O'Callaghan et al., 2020). Therefore, the FA supply via colostrum and transition milk determined the ALA status of the neonatal calf in the present study. Especially in calves of the EFA and EFA+CLA groups, high percentages of ALA in plasma fat, particularly in the TG, PL, and CE fractions, were accomplished after feeding of colostrum and milk during the first $5 \mathrm{~d}$ of life. In CE, ALA proportions up to $12 \%$ were observed after feeding on colostrum and milk from EFA-supplemented dams. Moreover, the correlation coefficients of ALA and LA were higher for the relationship of FA percentages between colostrum and calf plasma than between dam and calf plasma in the present study. This observation supported the assumption that the placental transfer of EFA is under tighter 
control than transfer via the mammary gland (Garcia et al., 2014a). Concordantly, Garcia et al. (2016) observed that the addition of LA to milk replacer modified plasma FA in calves to a greater degree than maternal supplementation with the FA during late gestation. An elevated LA supply via the mammary gland was also observed in sheep (Noble et al., 1978b). Furthermore, the percentages of LA and ALA are already increased in the first milking after parturition if the dam is supplemented with these FA (Santschi et al., 2009; Salehi et al., 2016). Consequently, feeding on colostrum and transition milk from EFA-supplemented dams improved the availability of EFA for young calves.

In contrast to ALA and LA, the percentage of n-3 and n- 6 metabolites, such as DPA, DHA, and ARA, decreased from d 1 to 5 of life in plasma fat and especially in plasma TG, PL, and CE. Furthermore, the proportions of PL and CE, where most of the n-3 and n-6 FA are stored (Christie, 1981; Palmquist, 2010), did not change from $\mathrm{d} 1$ to 5 . Consequently, the enrichment of DPA, DHA, and ARA in lipid fractions could not be maintained by colostrum feeding, as was the case for ALA and LA. Obviously, there is a preferred transport of ALA and LA via colostrum and milk feeding in neonatal calves, but this was not observed for n-3 and n- 6 metabolites. Only the EPA concentration did not decrease during the first $5 \mathrm{~d}$ of life in calves. This finding was surprising because the DPA concentration in colostrum indicated a higher enrichment of DPA than EPA in milk fat of EFA and EFA+CLA cows (Vogel et al., 2020). On the other hand, DHA was not detected in the milk fat of the cows (Vogel et al., 2020). Nevertheless, percentages of EPA, DPA, and DHA were higher in the plasma fat and especially in the PL fraction of calves whose dams received the EFA and EFA+CLA treatment than in calves from CTRL- and CLA-supplemented dams. However, it might be reasonable to supply neonatal calves with fish oil to increase availability of n-3 FA metabolites such as EPA and DHA, as recently shown by Opgenorth et al. (2020).

As mentioned above, n-3 and n-6 FA are primarily stored in the PL and CE lipid fractions (Christie, 1981; Palmquist, 2010). In the CE fraction, EPA clearly increased on d 5 only in EFA calves. Overall, the importance of placental and mammary transfer may depend on individual FA supplies, with milk transfer being critical for the neonatal ALA and LA supplies. The neonatal status of n-3 and n- 6 FA metabolites, especially DHA and ARA, obviously depends more on placental than mammary FA transfer. The present study did not allow us to distinguish between exogenous supplies and endogenous synthesis of n- 3 and n- 6 FA metabolites in the 5-d-old calves, but we assume that the endogenous syntheses were low due to the low $\Delta^{6}$ desaturase activ- ity in neonatal ruminants (Shand et al., 1978; Doreau et al., 2011).

In contrast to the limitations of placental CLA transport, the cis-9,trans-11 and trans-10,cis-12 CLA from CLA-supplemented dams were transferred to calves via colostrum and milk. The fact that cis-9,trans-11 CLA but not trans-10, cis-12 CLA increased in plasma fat of calves born by dams not treated with CLA mirrored the higher concentrations of cis-9,trans-11 than trans10,cis-12 CLA in colostrum and milk (Vogel et al., 2020). In calves from CLA-treated cows, both CLA isomers increased to a greater extent compared with those in calves without maternal CLA treatment. The additional increase due to CLA supplementation seemed to be comparable between the 2 CLA isomers. Due to the lower total trans-10,cis-12 CLA concentration in calves, this isomer was not detectable in individual lipid fractions of neonatal blood plasma, whereas cis-9,trans-11 CLA was elevated in calf TG, PL, and CE fractions after feeding on colostrum and milk from dams of the CLA groups. This omnidirectional incorporation of additionally available CLA into several lipid fractions was also observed in a previous study, in which supplemented cis-9,trans-11 CLA was channeled into several lipid classes of rat liver lipids (Banni et al., 2001).

\section{CONCLUSIONS}

The results of the present study suggest that an increased maternal EFA and CLA supply during late lactation improved the EFA and CLA status in the neonatal calves, primarily by an elevated supply via colostrum and transition milk feeding. The majority of EFA were stored in the PL and CE plasma fractions. In contrast to ALA and LA, n-3 and n-6 metabolites such as DHA and ARA were enriched in calves immediately after birth, supporting the concept of a preferred placental transfer of DHA and ARA in bovines. The FA supplementation of dams during late lactation indicated minor effects on gestation length and nutrient composition in colostrum and transition milk, slightly affecting nutrient intake after birth, but did not influence fetal and neonatal growth performance.

\section{ACKNOWLEDGMENTS}

We gratefully acknowledge B. Jentz, M. Dahm (Institute of Muscle Biology and Growth), and K. Karpati (Institute of Nutritional Physiology) at the Leibniz Institute for Farm Animal Biology (FBN), Dummerstorf, Germany, for analytical assistance. We further thank J. Gruse and S. Haubold (Institute of Nutritional Physiology, FBN) as well as the staff of the cattle facility and the experimental animal facility (FBN) for experimen- 
tal support. BASF (Ludwigshafen, Germany) is gratefully acknowledged for financial support of the study that provided the dams for the present experiment. The publication of this article was funded by the Open Access Fund of the Leibniz Institute for Farm Animal Biology (FBN). The authors declare that there are no conflicts of interest.

\section{REFERENCES}

Abayasekara, D. R. E., and D. C. Wathes. 1999. Effects of altering dietary fatty acid composition on prostaglandin synthesis and fertility. Prostaglandins Leukot. Essent. Fatty Acids 61:275-287. https: //doi.org/10.1054/plef.1999.0101.

Banni, S., G. Carta, E. Angioni, E. Murru, P. Scanu, M. P. Melis, D. E. Bauman, S. M. Fischer, and C. Ip. 2001. Distribution of conjugated linoleic acid and metabolites in different lipid fractions in the rat liver. J. Lipid Res. 42:1056-1061.

Barkema, H. W., M. A. G. von Keyserlingk, J. P. Kastelic, T. J. G. M. Lam, C. Luby, J.-P. Roy, S. J. LeBlanc, G. P. Keefe, and D. F. Kelton. 2015. Invited review: Changes in the dairy industry affecting dairy cattle health and welfare. J. Dairy Sci. 98:7426-7445. https://doi.org/10.3168/jds.2015-9377.

Bauman, D., L. Baumgard, B. Corl, and J. Griinari. 2000. Biosynthesis of conjugated linoleic acid in ruminants. J. Anim. Sci. 77 (ESuppl):1-15. https://doi.org/10.2527/jas2000.77E-Suppl1f.

Baumrucker, C. R., and R. M. Bruckmaier. 2014. Colostrogenesis: IgG(1) transcytosis mechanisms. J. Mammary Gland Biol. Neoplasia 19:103-117. https://doi.org/10.1007/s10911-013-9313-5.

Burr, G. O., and M. M. Burr. 1930. On the nature and role of the fatty acids essential in nutrition. J. Biol. Chem. 86:587-621.

Calder, P. C. 2012. Mechanisms of action of (n-3) fatty acids. J. Nutr. 142:592S-599S. https://doi.org/10.3945/jn.111.155259.

Castañeda-Gutiérrez, E., T. R. Overton, W. R. Butler, and D. E. Bauman. 2005. Dietary supplements of two doses of calcium salts of conjugated linoleic acid during the transition period and early lactation. J. Dairy Sci. 88:1078-1089. https://doi.org/10.3168/jds .S0022-0302(05)72775-2.

Chelikani, P. K., J. A. Bell, and J. J. Kennelly. 2004. Effects of feeding or abomasal infusion of canola oil in Holstein cows 1. Nutrient digestion and milk composition. J. Dairy Res. 71:279-287. https:/ /doi.org/10.1017/S0022029904000287.

Christie, W. W. 1981. The effects of diet and other factors on the lipid composition of ruminant tissues and milk. Pages 125-226 in Lipid Metabolism in Ruminant Animals. W. W. Christie, ed. Pergamon, Oxford, UK.

Coleman, D. N., K. C. Rivera-Acevedo, and A. E. Relling. 2018. Prepartum fatty acid supplementation in sheep I. Eicosapentaenoic and docosahexaenoic acid supplementation do not modify ewe and lamb metabolic status and performance through weaning. J. Anim. Sci. 96:364-374. https://doi.org/10.1093/jas/skx012.

Couvreur, S., C. Hurtaud, C. Lopez, L. Delaby, and J. L. Peyraud. 2006. The linear relationship between the proportion of fresh grass in the cow diet, milk fatty acid composition, and butter properties. J. Dairy Sci. 89:1956-1969. https://doi.org/10.3168/jds.S0022 -0302(06)72263-9.

Dänicke, S., J. Kowalczyk, L. Renner, J. Pappritz, U. Meyer, R. Kramer, E.-M. Weber, S. Döll, J. Rehage, and G. Jahreis. 2012. Effects of conjugated linoleic acids fed to dairy cows during early gestation on hematological, immunological, and metabolic characteristics of cows and their calves. J. Dairy Sci. 95:3938-3953. https://doi.org/ $10.3168 /$ jds.2011-4879.

Dannenberger, D., G. Nuernberg, K. Nuernberg, K. Will, N. Schauer, and M. Schmicke. 2017. Effects of diets supplemented with n-3 or n-6 PUFA on pig muscle lipid metabolites measured by nontargeted LC-MS lipidomic profiling. J. Food Compos. Anal. 56:47-54. https://doi.org/10.1016/j.jfca.2016.11.015.
Dannenberger, D., K. Nuernberg, G. Nuernberg, and A. Priepke. 2012. Different dietary protein and PUFA interventions alter the fatty acid concentrations, but not the meat quality, of porcine muscle. Nutrients 4:1237-1246. https://doi.org/10.3390/nu4091237.

Doreau, M., D. Bauchart, and Y. Chilliard. 2011. Enhancing fatty acid composition of milk and meat through animal feeding. Anim. Prod. Sci. 51:19-29. https://doi.org/10.1071/AN10043.

Duvaux-Ponter, C., K. Rigalma, S. Roussel-Huchette, Y. Schawlb, and A. A. Ponter. 2008. Effect of a supplement rich in linolenic acid, added to the diet of gestating and lactating goats, on the sensitivity to stress and learning ability of their offspring. Appl. Anim. Behav. Sci. 114:373-394. https://doi.org/10.1016/j.applanim.2008 .01.021.

Elmes, M., P. Tew, Z. Cheng, S. E. Kirkup, D. R. E. Abayasekara, P. C. Calder, M. A. Hanson, D. C. Wathes, and G. C. Burdge. 2004 The effect of dietary supplementation with linoleic acid to late gestation ewes on the fatty acid composition of maternal and fetal plasma and tissues and the synthetic capacity of the placenta for 2-series prostaglandins. Biochim. Biophys. Acta Mol. Cell Biol. Lipids 1686:139-147. https://doi.org/10.1016/j.bbalip.2004.09 .004 .

Ferlay, A., B. Martin, P. Pradel, J. B. Coulon, and Y. Chilliard. 2006. Influence of grass-based diets on milk fatty acid composition and milk lipolytic system in Tarentaise and Montbéliarde cow breeds. J. Dairy Sci. 89:4026-4041. https://doi.org/10.3168/jds.S0022 $-0302(06) 72446-8$

Garcia, M., L. F. Greco, M. G. Favoreto, R. S. Marsola, L. T. Martins, R. S. Bisinotto, J. H. Shin, A. L. Lock, E. Block, W. W. Thatcher, J. E. P. Santos, and C. R. Staples. 2014a. Effect of supplementing fat to pregnant nonlactating cows on colostral fatty acid profile and passive immunity of the newborn calf. J. Dairy Sci. 97:392405. https://doi.org/10.3168/jds.2013-7086.

Garcia, M., L. F. Greco, M. G. Favoreto, R. S. Marsola, D. Wang, J. H. Shin, E. Block, W. W. Thatcher, J. E. Santos, and C. R. Staples. 2014b. Effect of supplementing essential fatty acids to pregnant nonlactating Holstein cows and their preweaned calves on calf performance, immune response, and health. J. Dairy Sci. 97:5045-5064. https://doi.org/10.3168/jds.2013-7473.

Garcia, M., L. F. Greco, A. L. Lock, E. Block, J. E. P. Santos, W. W. Thatcher, and C. R. Staples. 2016. Supplementation of essential fatty acids to Holstein calves during late uterine life and first month of life alters hepatic fatty acid profile and gene expression. J. Dairy Sci. 99:7085-7101. https://doi.org/10.3168/jds.2015 $-10472$

Geiger, M., B. S. Mohammed, S. Sankarappa, and H. Sprecher. 1993. Studies to determine if rat liver contains chain-length-specific acylCoA 6-desaturases. Biochim. Biophys. Acta 1170:137-142. https:/ /doi.org/10.1016/0005-2760(93)90063-F.

Gnott, M., L. Vogel, C. Kröger-Koch, D. Dannenberger, A. Tuchscherer, A. Tröscher, E. Trevisi, T. Stefaniak, J. Bajzert, A. Starke, M. Mielenz, L. Bachmann, and H. M. Hammon. 2020. Changes in fatty acids in plasma and association with the inflammatory response in dairy cows abomasally infused with essential fatty acids and conjugated linoleic acid during late and early lactation. J. Dairy Sci. 103:11889-11910. https://doi.org/10.3168/jds.2020-18735.

Görs, S., M. Kucia, M. Langhammer, P. Junghans, and C. Metges. 2009. Milk composition in mice-Methodological aspects and effects of mouse strain and lactation day. J. Dairy Sci. 92:632-637. https://doi.org/10.3168/jds.2008-1563.

Grosvenor, C. E., M. F. Picciano, and C. R. Baumrucker. 1993. Hormones and growth-factors in milk. Endocr. Rev. 14:710-728. https: //doi.org/10.1210/edrv-14-6-710.

Haggarty, P. 2002. Placental regulation of fatty acid delivery and its effect on fetal growth - A review. Placenta 23:S28-S38. https://doi .org/10.1053/plac.2002.0791.

Hanebutt, F. L., H. Demmelmair, B. Schiessl, E. Larque, and B. Koletzko. 2008. Long-chain polyunsaturated fatty acid (LC-PUFA) transfer across the placenta. Clin. Nutr. 27:685-693. https://doi .org/10.1016/j.clnu.2008.05.010.

Haubold, S., C. Kröger-Koch, A. Starke, A. Tuchscherer, A. Tröscher, H. Kienberger, M. Rychlik, U. Bernabucci, E. Trevisi, and H. M. 
Hammon. 2020. Effects of abomasal infusion of essential fatty acids and conjugated linoleic acid on performance and fatty acid, antioxidative, and inflammatory status in dairy cows. J. Dairy Sci. 103:972-991. https://doi.org/10.3168/jds.2019-17135.

Herrera, E. 2002. Implications of dietary fatty acids during pregnancy on placental, fetal and postnatal development - A review. Placenta 23:S9-S19. https://doi.org/10.1053/plac.2002.0771.

Hill, T. M., H. G. Bateman 2nd, J. M. Aldrich, and R. L. Schlotterbeck. 2009. Effects of changing the essential and functional fatty acid intake of dairy calves. J. Dairy Sci. 92:670-676. https://doi .org $/ 10.3168 /$ jds.2008-1368.

Hötger, K., H. M. Hammon, C. Weber, S. Gors, A. Troscher, R. M. Bruckmaier, and C. C. Metges. 2013. Supplementation of conjugated linoleic acid in dairy cows reduces endogenous glucose production during early lactation. J. Dairy Sci. 96:2258-2270. https:/ /doi.org/10.3168/jds.2012-6127.

Innis, S. M. 2005. Essential fatty acid metabolism during early development. Pages 235-274 in Biology of Metabolism in Growing Animals. Vol. 3. D. G. Burrin and H. J. Mersmann, ed. Elsevier, London, UK.

Jump, D. B. 2008. N-3 polyunsaturated fatty acid regulation of hepatic gene transcription. Curr. Opin. Lipidol. 19:242-247. https:// doi.org/10.1097/MOL.0b013e3282ffaf6a.

Kay, J. K., J. R. Roche, E. S. Kolver, N. A. Thomson, and L. H. Baumgard. 2005. A comparison between feeding systems (pasture and TMR) and the effect of vitamin E supplementation on plasma and milk fatty acid profiles in dairy cows. J. Dairy Res. 72:322332. https://doi.org/10.1017/S0022029905000944.

Kelly, M. L., E. S. Kolver, D. E. Bauman, M. E. Van Amburgh, and L. D. Muller. 1998. Effect of intake of pasture on concentrations of conjugated linoleic acid in milk of lactating cows. J. Dairy Sci. 81:1630-1636. https://doi.org/10.3168/jds.S0022-0302(98)75730 $-3$.

Kelsey, J. A., B. A. Corl, R. J. Collier, and D. E. Bauman. 2003. The effect of breed, parity, and stage of lactation on conjugated linoleic acid (CLA) in milk fat from dairy cows. J. Dairy Sci. 86:25882597. https://doi.org/10.3168/jds.S0022-0302(03)73854-5.

Koletzko, B., E. Lien, C. Agostoni, H. Böhles, C. Campoy, I. Cetin, T. Decsi, J. W. Dudenhausen, C. DuPont, S. Forsyth, I. Hoesli, W. Holzgreve, A. Lapillonne, G. Putet, N. J. Secher, M. Symonds, H. Szajewska, P. Willatts, and R. Uauy. 2008. The roles of long-chain polyunsaturated fatty acids in pregnancy, lactation and infancy: Review of current knowledge and consensus recommendations. J. Perinat. Med. 36:5-14. https://doi.org/10.1515/JPM.2008.001.

Kühne, S., H. M. Hammon, R. M. Bruckmaier, C. Morel, Y. Zbinden, and J. W. Blum. 2000. Growth performance, metabolic and endocrine traits, and absorptive capacity in neonatal calves fed either colostrum or milk replacer at two levels. J. Anim. Sci. 78:609-620. https://doi.org/10.2527/2000.783609x.

Lahlou, M. N., R. Kanneganti, L. J. Massingill, G. A. Broderick, Y. Park, M. W. Pariza, J. D. Ferguson, and Z. Wu. 2014. Grazing increases the concentration of CLA in dairy cow milk. Animal 8:1191-1200. https://doi.org/10.1017/S1751731114000998.

Lerch, S., J. A. Pires, C. Delavaud, K. J. Shingfield, D. Pomies, B. Martin, Y. Chilliard, and A. Ferlay. 2015. Rapeseed or linseed in dairy cow diets over 2 consecutive lactations: Effects on adipose fatty acid profile and carry-over effects on milk fat composition in subsequent early lactation. J. Dairy Sci. 98:1005-1018. https://doi .org/10.3168/jds.2014-8578.

Madsen, B. D., M. D. Rasmussen, M. O. Nielsen, L. Wiking, and L. B. Larsen. 2004. Physical properties of mammary secretions in relation to chemical changes during transition from colostrum to milk. J. Dairy Res. 71:263-272. https://doi.org/10.1017/ S0022029904000263.

Moallem, U. 2018. Invited review: Roles of dietary n-3 fatty acids in performance, milk fat composition, and reproductive and immune systems in dairy cattle. J. Dairy Sci. 101:8641-8661. https://doi .org/10.3168/jds.2018-14772.

Moallem, U., and M. Zachut. 2012. Short communication: The effects of supplementation of various n-3 fatty acids to late-pregnant dairy cows on plasma fatty acid composition of the newborn calves. J. Dairy Sci. 95:4055-4058. https://doi.org/10.3168/jds.2012-5457.

Nagao, K., and T. Yanagita. 2005. Conjugated fatty acids in food and their health benefits. J. Biosci. Bioeng. 100:152-157. https://doi .org/10.1263/jbb.100.152.

Neuringer, M., W. E. Connor, D. S. Lin, L. Barstad, and S. Luck. 1986. Biochemical and functional effects of prenatal and postnatal omega 3 fatty acid deficiency on retina and brain in rhesus monkeys. Proc. Natl. Acad. Sci. USA 83:4021-4025. https://doi.org/ 10.1073/pnas.83.11.4021.

Nickles, K. R., L. Hamer, D. N. Coleman, and A. E. Relling. 2019. Supplementation with eicosapentaenoic and docosahexaenoic acids in late gestation in ewes changes adipose tissue gene expression in the ewe and growth and plasma concentration of ghrelin in the offspring. J. Anim. Sci. 97:2631-2643. https://doi.org/10.1093/ jas/skz141.

Noble, R. C., J. H. Shand, A. W. Bell, G. E. Thompson, and J. H. Moore. 1978a. The transfer of free palmitic and linoleic acids across the ovine placenta. Lipids 13:610-615. https://doi.org/10 $.1007 / \mathrm{BF} 02535824$.

Noble, R. C., J. H. Shand, and D. T. Calvert. 1982. The role of the placenta in the supply of essential fatty acids to the fetal sheep: studies of lipid compositions at term. Placenta 3:287-295. https:// doi.org/10.1016/S0143-4004(82)80005-2.

Noble, R. C., J. H. Shand, J. T. Drummond, and J. H. Moore. 1978b. "Protected" polyunsaturated fatty acid in the diet of the ewe and the essential fatty acid status of the neonatal lamb. J. Nutr. 108:1868-1876. https://doi.org/10.1093/jn/108.11.1868.

NRC. 2001. Nutrient Requirements of Dairy Cattle. 7th rev. ed. Natl. Acad. Press, Washington, D.C.

Nudda, A., D. L. Palmquist, G. Battacone, S. Fancellu, S. P. G. Rassu, and G. Pulina. 2008. Relationships between the contents of vaccenic acid, CLA and $n-3$ fatty acids of goat milk and the muscle of their suckling kids. Livest. Sci. 118:195-203. https://doi.org/10 $.1016 /$ j.livsci.2008.01.020.

O'Callaghan, T. F., M. O'Donovan, J. P. Murphy, K. Sugrue, D. Mannion, W. P. McCarthy, M. Timlin, K. N. Kilcawley, R. M. Hickey, and J. T. Tobin. 2020. Evolution of the bovine milk fatty acid profile - From colostrum to milk five days post parturition. Int. Dairy J. 104:104655. https://doi.org/10.1016/j.idairyj.2020.104655.

Odens, L. J., R. Burgos, M. Innocenti, M. J. VanBaale, and L. H. Baumgard. 2007. Effects of varying doses of supplemental conjugated linoleic acid on production and energetic variables during the transition period. J. Dairy Sci. 90:293-305. https://doi.org/10 .3168/jds.S0022-0302(07)72630-9.

Olsen, S. F., J. D. Sørensen, N. Secher, M. Hedegaard, T. B. Henriksen, H. S. Hansen, and A. Grant. 1992. Randomized controlled trial of effect of fish-oil supplementation on pregnancy duration. Lancet 339:1003-1007. https://doi.org/10.1016/0140-6736(92)90533-9.

Opgenorth, J., L. M. Sordillo, A. L. Lock, J. C. Gandy, and M. J. VandeHaar. 2020. Colostrum supplementation with n-3 fatty acids alters plasma polyunsaturated fatty acids and inflammatory mediators in newborn calves. J. Dairy Sci. 103:11676-11688. https:// doi.org/10.3168/jds.2019-18045.

Palmquist, D. L. 2010. Essential fatty acids in ruminant diets. Pages 127-141 in Proc. 21st Annual Ruminant Nutrition Symposium, Gainesville, FL. Institute of Food and Agricultural Sciences, University of Florida, Gainesville, FL.

Park, J. C., Y. H. Kim, H. J. Jung, H. K. Moon, O. S. Kwon, and B. D. Lee. 2005. Effects of dietary supplementation of conjugated linoleic acid (CLA) on piglets' growth and reproductive performance in sows. Asian-Aust. J. Anim. Sci. 18:249-254. https://doi.org/10 .5713 /ajas.2005.249.

Pickard, R. M., A. Beard, C. Seal, and S. Edwards. 2008. Neonatal lamb vigor is improved by feeding docosahexaenoic acid in the form of algal biomass during late gestation. Animal 2:1186-1192. https://doi.org/10.1017/S1751731108001997.

Salehi, R., and D. J. Ambrose. 2017. Prepartum maternal diets supplemented with oilseeds alter the fatty acid profile in bovine neonatal plasma possibly through reduced placental expression of fatty acid 
transporter protein 4 and fatty acid translocase. Reprod. Fertil. Dev. 29:1846-1855. https://doi.org/10.1071/RD15476.

Salehi, R., D. J. Ambrose, and M. Oba. 2016. Short communication: Effects of prepartum diets supplemented with rolled oilseeds on Brix values and fatty acid profile of colostrum. J. Dairy Sci. 99:3598-3601. https://doi.org/10.3168/jds.2015-10189.

Santschi, D. E., H.-R. Wettstein, F. Leiber, A.-K. M. Witschi, and M. Kreuzer. 2009. Colostrum and milk fatty acids of dairy cows as influenced by extruded linseed supplementation during the transition period. Can. J. Anim. Sci. 89:383-392. https://doi.org/10 .4141/CJAS08115.

Segovia, S. A., M. H. Vickers, X. Y. D. Zhang, C. Gray, and C. M. Reynolds. 2015. Maternal supplementation with conjugated linoleic acid in the setting of diet-induced obesity normalizes the inflammatory phenotype in mothers and reverses metabolic dysfunction and impaired insulin sensitivity in offspring. J. Nutr. Biochem. 26:1448-1457. https://doi.org/10.1016/j.jnutbio.2015.07.013.

Shand, J. H., R. C. Noble, and J. H. Moore. 1978. Dietary influences on fatty acid metabolism in the liver of the neonatal lamb. Biol. Neonate 34:217-224. https://doi.org/10.1159/000241132.

Shingfield, K. J., L. Bernard, C. Leroux, and Y. Chilliard. 2010. Role of trans fatty acids in the nutritional regulation of mammary lipogenesis in ruminants. Animal 4:1140-1166. https://doi.org/10 $.1017 /$ S1751731110000510.

Shokryazdan, P., M. A. Rajion, G. Y. Meng, L. J. Boo, M. Ebrahimi, M. Royan, M. Sahebi, P. Azizi, R. Abiri, and M. F. Jahromi. 2017.
Conjugated linoleic acid: A potent fatty acid linked to animal and human health. Crit. Rev. Food Sci. Nutr. 57:2737-2748. https:// doi.org/10.1080/10408398.2015.1060190.

Vogel, L., M. Gnott, C. Kröger-Koch, D. Dannenberger, A. Tuchscherer, A. Tröscher, H. Kienberger, M. Rychlik, A. Starke, L. Bachmann, and H. M. Hammon. 2020. Effects of abomasal infusion of essential fatty acids together with conjugated linoleic acid in late and early lactation on performance, milk and body composition, and plasma metabolites in dairy cows. J. Dairy Sci. 103:7431-7450. https://doi.org/10.3168/jds.2019-18065.

Vogel, L., M. Gnott, C. Kröger-Koch, S. Görs, J. M. Weitzel, E. Kanitz, A. Hoeflich, A. Tuchscherer, A. Tröscher, J. J. Gross, R. M. Bruckmaier, A. Starke, L. Bachmann, and H. M. Hammon. 2021. Glucose metabolism and the somatotropic axis in dairy cows after abomasal infusion of essential fatty acids together with conjugated linoleic acid during late gestation and early lactation. J. Dairy Sci. 104:3646-3664. https://doi.org/10.3168/jds.2020-19321.

\section{ORCIDS}

K. L. Uken (® https://orcid.org/0000-0002-4877-7690

D. Dannenberger @ https://orcid.org/0000-0002-5201-0935

A. Tröscher (i) https://orcid.org/0000-0002-4198-4427

H. M. Hammon (i) https://orcid.org/0000-0001-8698-1257 